\title{
əAccurate Absolute Measurements of Liquid Water Content (LWC) and Ice Water Content (IWC) of Clouds and Precipitation with Spectrometric Water Raman Lidar
}

\author{
Jens Reichardt, ${ }^{\mathrm{a}}$ Christine Knist, ${ }^{\mathrm{a}}$ NATAlia Kouremeti, ${ }^{\mathrm{b}}$ William Kitchin, ${ }^{\mathrm{c}}$ And TARAs Plakhotnik ${ }^{\mathrm{c}}$ \\ ${ }^{\text {a } R i c h a r d-A ß m a n n-O b s e r v a t o r i u m, ~ D e u t s c h e r ~ W e t t e r d i e n s t, ~ L i n d e n b e r g, ~ G e r m a n y ~}$ \\ ${ }^{\mathrm{b}}$ Physikalisch-Meteorologisches Observatorium Davos/World Radiation Center, Davos Dorf, Switzerland \\ ${ }^{\mathrm{c}}$ School of Mathematics and Physics, University of Queensland, Saint Lucia, Queensland, Australia
}

(Manuscript received 8 June 2021, in final form 20 August 2021)

\begin{abstract}
A detailed description is given of how the liquid water content (LWC) and the ice water content (IWC) can be determined accurately and absolutely from the measured water Raman spectra of clouds. All instrumental and spectroscopic parameters that affect the accuracy of the water-content measurement are discussed and quantified; specifically, these are the effective absolute differential Raman backscattering cross section of water vapor $d \sigma_{\text {vap }}^{\text {eff }}(\pi) / d \Omega$, and the molecular Raman backscattering efficiencies $\eta_{\text {liq }}$ and $\eta_{\text {ice }}$ of liquid and frozen microparticles, respectively. The latter two are determined following rigorous theoretical approaches combined with Raman Lidar for Atmospheric Moisture Sensing (RAMSES) measurements. For $\eta_{\text {ice, }}$, this includes a new experimental method that assumes continuity of the number of water molecules across the vertical extent of the melting layer. Examples of water-content measurements are presented, including supercooled liquid-water clouds and melting layers. Error sources are discussed; one effect that stands out is interfering fluorescence by aerosols. Aerosol effects and calibration issues are the main reasons why spectral Raman measurements are required for quantitative measurements of LWC and IWC. The presented study lays the foundation for cloud microphysical investigations and for the evaluation of cloud models or the cloud data products of other instruments. As a first application, IWC retrieval methods are evaluated that are based on either lidar extinction or radar reflectivity measurements. While the lidar-based retrievals show unsatisfactory agreement with the RAMSES IWC measurements, the radar-based IWC retrieval which is used in the Cloudnet project performs reasonably well. On average, retrieved IWC agrees within $20 \%$ to $30 \%$ (dry bias) with measured IWC.
\end{abstract}

KEYWORDS: Cirrus clouds; Cloud microphysics; Cloud water/phase; Lidars/Lidar observations

\section{Introduction}

Water content and phase of clouds are key to a better understanding of weather and climate processes (Baker 1997; Illingworth et al. 2007), and so considerable research effort has been dedicated to measuring these quantities over the last decades, be it in situ or remotely. Active remote sensing of liquid water content (LWC) and ice water content (IWC) from the ground, from aircraft and satellites is attempted using lidar or radar. Early studies explored techniques that were based on different combinations of both (Intrieri et al. 1993; Donovan and van Lammeren 2001; Wang and Sassen 2002), in some cases augmented by using different sensors (Delanoë and Hogan 2008), or multiple radars (Gaussiat et al. 2003). These multi-instrument observations are costly, and the synergistic approach is inherently difficult. Therefore, interest in single-instrument methods developed and continues in parallel to this day, starting with a radar retrieval of LWC (Ovtchinnikov and Kogan 2000). Somewhat later, retrieval methods for IWC were proposed as well, either based on a single lidar (Heymsfield et al. 2005, 2014), or radar (Hogan et al. 2006). But all these methods share the same shortcoming: the LWC and IWC estimates provided are

¿ Denotes content that is immediately available upon publication as open access.

Corresponding author: Jens Reichardt, jens.reichardt@dwd.de derived from observables that are not directly connected to water content, because extinction and elastic scattering of light or reflectivity of radio waves depend strongly on particle size, shape, and orientation and not on water mass per volume.

A solution to this problem exploits the Raman effect. Raman scattering is active in all physical states. In vapor, scattering is proportional to the number of water molecules. Raman spectra of water vapor, liquid water, and ice, although overlapping, can be easily separated due to their specific spectral characteristics (Slusher and Derr 1975; D'Arrigo et al. 1981; Pershin and Bunkin 1998; Suzuki et al. 2012; Plakhotnik and Reichardt 2017). One instrumental line of development followed the approach to measure not only the Raman scattering of water vapor but also that of water condensate by means of an additional discrete detection channel (Whiteman and Melfi 1999; Veselovskii et al. 2000; Rizi et al. 2004; Wang et al. 2004; Sakai et al. 2013). The advantage of a simple instrument setup is obvious, but it turned out that measurements with these instruments are difficult to calibrate and can hardly be corrected for interfering signals such as the fluorescence of aerosols. Probably because of these obstacles, until today, there is no lidar of this type that could provide reliable continuous measurements of LWC or IWC.

The competing experimental development line, a spectrometric lidar, is technically more complex. With this instrument,

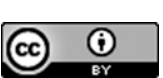

This article is licensed under a Creative Commons Attribution 4.0 license (http://creativecommons.org/ licenses/by/4.0/). 
spectrally resolved measurements of the complete water Raman spectrum could be performed which would hold the prospect of resolving the before-mentioned issues. The pioneering work by Bukin et al. (1983) and especially Arshinov et al. (2002), who examined the Raman spectrum of fog and liquid-water clouds for the first time, ignited vivid research activity in this field (Kim et al. 2009; Park et al. 2010; Sakai et al. 2013; Liu and Yi 2013). Eventually, Reichardt (2012, 2014, hereinafter referred to as R14) showed for the first time how calibrated Raman spectra of clouds can be obtained with spectrometric water lidars such as the Raman Lidar for Atmospheric Moisture Sensing (RAMSES) at the Lindenberg Meteorological Observatory of the German Meteorological Service (Reichardt et al. 2012). These measurements opened up the perspective of direct determination of IWC and LWC. However, this task proved to be quite challenging. Unlike with water vapor, no high-quality data from other instruments are readily available for comparison, so the water-content measurement could not be calibrated relative to some external reference profile but instead calibration had to be absolute.

This contribution describes in detail the steps necessary to get from the lidar measurement of the Raman spectrum of a cloud to its water content, thereby continuing the work by R14. First, section 2 gives an overview of the instrumental and spectroscopic parameters that determine the accuracy of the water-content measurement. Section 3 elaborates these parameters and quantifies them, starting with the careful characterization of the RAMSES water spectrometer (section $3 a$ ). Then sections $3 b$ and $3 c$ present theoretical results obtained for the relative Raman cross section for droplets and ice particles, respectively. Examples of particularly interesting water-content measurements are discussed in section 4 together with error sources such as interfering fluorescence by aerosols. Section 5 presents the results of a study dedicated to the evaluation of broadly used IWC retrieval methods. Finally, section 6 summarizes the findings and briefly discusses ongoing and future application of the new measuring technique.

\section{Theory}

\section{a. Spectrum calibration}

According to R14, the profile of the calibrated Raman backscatter coefficient spectrum $S(z)$ as measured with the water spectrometer can be written in aggregate form as [R14, Eq. (11)]

$$
S(z)=\left\{\beta\left(\lambda_{1}, z\right), \beta\left(\lambda_{2}, z\right), \ldots, \beta\left(\lambda_{32}, z\right)\right\},
$$

with $\beta\left(\lambda_{i}, z\right)$ being the spectral backscattering coefficient at center wavelength $\lambda_{i}$ of detection channel $i, 1 \leq i \leq 32$, and height $z$. Depending on height and wavelength, $\beta$ consists of varying contributions from the Raman spectra of $\mathrm{N}_{2}\left(\beta_{\text {nit }}\right)$, water ice $\left(\beta_{\text {ice }}\right)$, liquid water $\left(\beta_{\text {liq }}\right)$, and water vapor $\left(\beta_{\text {vap }}\right)$, and the fluorescence spectrum of atmospheric aerosols $\left(\beta_{\mathrm{aer}}\right)$.

Neglecting differential overlap and light extinction by atmospheric particles for clarity, one can find the following expression for the ratio of detector signals $N^{\prime}\left(\lambda_{i}, z\right)$ to $N^{\prime}\left(\lambda_{\text {nit }}, z\right)$ :

$$
\frac{N^{\prime}\left(\lambda_{i}, z\right)}{N^{\prime}\left(\lambda_{\text {nit }}, z\right)}=k_{\text {cal }} \frac{\beta\left(\lambda_{i}, z\right)}{\beta_{\text {nit }}^{\text {eff }}\left(\lambda_{\text {nit }}, z\right)},
$$

and specifically [R14, Eq. (9)]

$$
\frac{N^{\prime}\left(\lambda_{\text {vap }}, z\right)}{N^{\prime}\left(\lambda_{\text {nit }}, z\right)}=k_{\text {cal }} \frac{\beta_{\text {vap }}^{\text {eff }}\left(\lambda_{\text {vap }}, z\right)}{\beta_{\text {nit }}^{\text {eff }}\left(\lambda_{\text {nit }}, z\right)} .
$$

Here, $N^{\prime}$ denotes the measured signal corrected for dead-time effects, background light, clear-air light transmission, and relative receiver efficiency; $N^{\prime}\left(\lambda_{\text {nit }}\right)$ and $N^{\prime}\left(\lambda_{\text {vap }}\right)$ are the signals of those detector channels whose spectral bandwidths include the $Q$ branch wavelengths $\lambda_{\text {nit }}$ of molecular nitrogen and $\lambda_{\text {vap }}$ of water vapor, respectively. To indicate that the Raman differential backscattering cross sections, $d \sigma^{\text {eff }}(\pi) / d \Omega$, of each channel effectively depend on the spectrometer function and the position of the $Q$ branch wavelength relative to the channel center wavelength, the superscript "eff" is inserted.

The calibration constant $k_{\text {cal }}$ is obtained from Eq. (3) using the water-vapor Raman method. Its defining equation can be found as Eq. (10) of R14. However, the notation is not optimum for the following discussion of quantitative water-content measurements and therefore has to be reformulated to show explicitly the dependence of $k_{\text {cal }}$ on $d \sigma^{\text {eff }}(\pi) / d \Omega$ :

$$
k_{\mathrm{cal}}^{-1}=K \frac{d \sigma_{\mathrm{vap}}^{\mathrm{eff}}(\pi) / d \Omega}{d \sigma_{\mathrm{nit}}^{\mathrm{eff}}(\pi) / d \Omega},
$$

with $K$ a constant.

Substituting $k_{\text {cal }}$ in Eq. (2) with the expression of Eq. (4), one obtains for $\beta\left(\lambda_{i}, z\right)$ :

$$
\begin{aligned}
\beta\left(\lambda_{i}, z\right) & =k_{\text {cal }}^{-1} \beta_{\text {nit }}^{\text {eff }}\left(\lambda_{\text {nit }}, z\right) \frac{N^{\prime}\left(\lambda_{i}, z\right)}{N^{\prime}\left(\lambda_{\text {nit }}, z\right)} \\
& =k_{\text {cal }}^{-1} \frac{d \sigma_{\text {nit }}^{\text {eff }}(\pi)}{d \Omega} c_{\text {nit }} n(z) \frac{N^{\prime}\left(\lambda_{i}, z\right)}{N^{\prime}\left(\lambda_{\text {nit }}, z\right)} \\
& =K^{\prime} \frac{d \sigma_{\text {vap }}^{\text {eff }}(\pi)}{d \Omega} n(z) \frac{N^{\prime}\left(\lambda_{i}, z\right)}{N^{\prime}\left(\lambda_{\text {nit }}, z\right)},
\end{aligned}
$$

with $K^{\prime}=K c_{\text {nit }}, c_{\text {nit }}$ the atmospheric $\mathrm{N}_{2}$ fraction, and $n$ the molecule number density of air (obtained from the 6-hourly radiosonde soundings at Lindenberg). As evident from Eq. (7), the results of the calibration procedure do not depend on the effective Raman differential backscattering cross section of $\mathrm{N}_{2}$; however, this is not the case for $d \sigma_{\text {vap }}^{\text {eff }}(\pi) / d \Omega$. The backscatter spectrum as a whole is linearly proportional to $d \sigma_{\text {vap }}^{\text {eff }}(\pi) / d \Omega$, and thus its accurate determination is of great significance for the anticipated absolute water-content measurements.

\section{b. Spectrum decomposition}

After calibration, the Raman spectra of liquid and frozen water have to be extracted from $S$. Here the difficulties are not only that the ice Raman spectrum $\left(S_{\text {ice }}, 395<\lambda<407 \mathrm{~nm}\right)$ 
overlaps with the one of liquid water $\left(S_{\text {liq }}, 395<\lambda<410 \mathrm{~nm}\right)$, but also that the Raman spectrum of water vapor $\left(S_{\text {vap }}\right.$, $403<\lambda<414 \mathrm{~nm}$ ) and the broadband fluorescence spectrum of atmospheric aerosols $\left(S_{\text {aer }}\right)$ interfere. As a first step, the aerosol effect is removed. This is done by calculating the mean spectral backscatter coefficient of the so-called reference spectrum $S_{\text {ref }}$ [R14, Eq. (13)] where only aerosol fluorescence is observed and subtracting it from $\beta\left(\lambda_{i}, z\right)\left(\lambda_{i}>395 \mathrm{~nm}\right)$. Neglecting a possible wavelength dependence of the aerosol fluorescence can cause a fluorescence residual in the $15-\mathrm{nm}$ range of the water Raman spectrum, but analysis of cloud-free but aerosol-laden air masses indicate that the associated error, if detectable at all, is minute (Fig. 5, R14). Incidentally, aerosol fluorescence can have a detrimental effect on water-content measurements if not accounted for, as will be demonstrated in section 4. It can only be corrected for in measurements with spectrometric water Raman lidars, observations with lidars utilizing discrete condensate detection channels are doomed to failure.

Next, the water-vapor Raman spectrum is subtracted, for a detailed description of the procedure see R14. Generally, the vapor spectrum used for the correction is determined from the actual measurement profile at cloud-free heights. If atmospheric conditions do not permit this approach, a reference water-vapor Raman spectrum obtained from previous measurements is adopted instead with the temperature $(T)$ dependence taken into account. The resultant condensate Raman spectrum $S_{\text {con }}=S_{\text {liq }}+S_{\text {ice }}$ is then decomposed to get $S_{\text {liq }}$ and $S_{\text {ice, }}$, and finally the total liquid-water and ice Raman backscatter coefficients $\beta_{\text {liq }}^{\mathrm{R}}$ and $\beta_{\text {ice }}^{\mathrm{R}}$, respectively, are calculated by integrating the corresponding spectra (see R14).

One side effect of the vapor correction is that for wavelengths longer than approximately $407 \mathrm{~nm}$ the Raman spectrum of liquid water becomes unreliable because here Raman scattering by water vapor dominates and so subtraction of this spectral contribution leads to significant statistical errors of the residual. To minimize this error introduced into $\beta_{\text {liq }}^{\mathrm{R}}$, the theoretical spectrum of liquid-water (Slusher and Derr 1975) is fitted to $S_{\text {liq }}$ for $\lambda<406 \mathrm{~nm}$. Spectrum integration is then performed over the actual measurement and the fitted theoretical spectrum for wavelengths shorter and longer than $406 \mathrm{~nm}$, respectively. The process is discussed in more detail in section 4 .

\section{c. Calculation of LWC and IWC}

LWC and IWC can then be calculated from $\beta_{\text {liq }}^{\mathrm{R}}$ and $\beta_{\text {ice }}^{\mathrm{R}}$ according to the following equations:

$$
\begin{aligned}
& \mathrm{LWC}=m_{\mathrm{H}_{2} \mathrm{O}}\left[\frac{d \sigma_{\text {liq }}^{\mathrm{mic}}(\pi)}{d \Omega}\right]^{-1} \beta_{\text {liq }}^{\mathrm{R}}, \\
& \mathrm{IWC}=m_{\mathrm{H}_{2} \mathrm{O}}\left[\frac{d \sigma_{\text {ice }}^{\mathrm{mic}}(\pi)}{d \Omega}\right]^{-1} \beta_{\text {ice }}^{\mathrm{R}},
\end{aligned}
$$

with $m_{\mathrm{H}_{2} \mathrm{O}}$ the mass of a water molecule, and $d \sigma^{\mathrm{mic}}(\pi) / d \Omega$ the differential Raman backscatter cross section for the individual water molecule in the liquid or ice phase. The superscript "mic" is intended to indicate that the molecular backscatter cross section of the water molecule in a microscopic cloud particle has to be applied. Because of shape-dependent formation of internal fields (Plakhotnik and Reichardt 2018), which ultimately influences the spatial distribution of the emitted Raman radiation, its numerical value depends on the shape and size of the particle and, in particular, differs significantly from $d \sigma^{\mathrm{mac}}(\pi) / d \Omega$, the differential Raman backscatter cross section determined in laboratory experiments for largevolume samples (ice or liquid water).

Be $\eta$ the efficiency with which microparticles emit Raman light in the backward direction as compared to the bulk sample:

$$
\eta=\frac{d \sigma^{\mathrm{mic}}(\pi) / d \Omega}{d \sigma^{\mathrm{mac}}(\pi) / d \Omega}
$$

then Eqs. (8) and (9) can be rewritten as

$$
\begin{aligned}
& \mathrm{LWC}=m_{\mathrm{H}_{2} \mathrm{O}}\left[\eta_{\mathrm{liq}} \frac{d \sigma_{\mathrm{liq}}^{\mathrm{mac}}(\pi)}{d \Omega}\right]^{-1} \beta_{\mathrm{liq}}^{\mathrm{R}}, \\
& \mathrm{IWC}=m_{\mathrm{H}_{2} \mathrm{O}}\left[\eta_{\mathrm{ice}} \frac{d \sigma_{\mathrm{ice}}^{\mathrm{mac}}(\pi)}{d \Omega}\right]^{-1} \beta_{\text {ice }}^{\mathrm{R}} .
\end{aligned}
$$

In summary, because $d \sigma^{\text {mac }}(\pi) / d \Omega$ is known with high accuracy for both bulk liquid water and ice (Plakhotnik and Reichardt 2017), the key to absolute measurements of cloud water content with spectrometric Raman lidars is an accurate determination of the effective Raman backscattering cross section of water vapor, $d \sigma_{\text {vap }}^{\text {eff }}(\pi) / d \Omega$, and a quantitative understanding of relative Raman scattering $\eta_{\text {liq }}$ and $\eta_{\text {ice. }}$. While the former is specific to each instrument, the latter is universal in nature and broadly applicable. The research efforts necessary to quantify $d \sigma_{\text {vap }}^{\text {eff }}(\pi) / d \Omega$ for the RAMSES water spectrometer, $\eta_{\text {liq }}$ and $\eta_{\text {ice }}$ are presented in section 3 .

\section{Determining the key parameters for $\mathrm{LWC}$ and IWC measurements}

\section{a. Spectrometer function and effective Raman backscattering cross section of water vapor}

In late November 2017 the RAMSES receiver was disassembled, and the water spectrometer including the coupling fiber was transferred to the ATLAS facility of the World Radiation Center in Davos, Switzerland, for spectral characterization which is necessary for an accurate determination of the effective Raman backscattering cross section of water vapor.

\section{1) AtLAS FACILITy}

The key component of the ATLAS system is an nspulsed optical parametric oscillator (OPO) laser (EKSPLA NT242) with a wide tuning range (210-2600 nm). Pulse spectral width, duration, and repetition rate are $5.7 \mathrm{pm}$ full width at half maximum $(\mathrm{FWHM}),<10 \mathrm{~ns}$, and $1000 \mathrm{~Hz}$, respectively. A microlens array homogenizes the 
radiation field of the laser pulse in the plane of the front face of the RAMSES fiber. A wedge filter is used to divert a small light fraction $(20 \%)$ to a wavemeter (Laser Spectrum Analyzer, HighFinesse GmbH, Germany; uncertainty $<1 \mathrm{pm}$ ) and an energy monitor device, which is a pyroelectric radiometer with a responsivity that is spectrally uniform within $0.5 \%$. The attached electrometer (Keithley 6517B) has been calibrated based on the quality management system of Physikalisch-Meteorologisches Observatorium Davos/World Radiation Center (PMOD/WRC).

ATLAS is computer-controlled so that automatic operation is possible and measurement sequences are selectable (Gröbner et al. 2016). For the first time ATLAS was used to characterize a time-resolving spectrometer, which made changes to the system software necessary. To enable direct communication between ATLAS and the RAMSES spectrometer, a local area network was set up. Thus, vital ATLAS status information could be stored in real time together with the spectrum data.

One noticeable difference between a routine lidar measurement and the ATLAS experiment is that the fiber is shone on directly instead of being illumined by backscattered light, which means that the effective bin width of the spectrometer is comparable to the ATLAS pulse length and thus much smaller than the range bin of the multichannel scalers $(200 \mathrm{~ns})$. The short illumination time and the therefore transiently high count rates require low signal intensities, and have to be taken into account when the signals are corrected for nonlinearities.

\section{2) Measurement Results}

To investigate the spectrometer response in the range of the water-vapor spectrum, two experiments were conducted: 1) ATLAS was tuned in the range from 405.0 to $409.0 \mathrm{~nm}$ with a step width of $50 \mathrm{pm}$, and the water spectrometer was operated with a fixed center wavelength (CWL) of $397.0 \mathrm{~nm}$ (standard setting). Scans were performed for three different signal attenuations. Because of the relatively slow detector electronics, data were measured with an effective ATLAS pulse repetition frequency of $125 \mathrm{~Hz}$. Measurement time per wavelength step was $130 \mathrm{~s}$. Additionally, a control run with ultralow light intensity (count rate $<1 \mathrm{Ms}^{-1} ; 200 \mathrm{pm}$ resolution, $340 \mathrm{~s}$ integration time) was completed. 2) The ATLAS wavelength was set at the $Q$ branch of the water-vapor Raman spectrum $(407.5 \mathrm{~nm}$ for the RAMSES transmitter wavelength of $354.72 \mathrm{~nm}$ ), and the water spectrometer CWL was tuned between 396.7 and 397.3 $\mathrm{nm}$ (50 pm step width, $100 \mathrm{~s}$ integration time).

Figure 1 presents the signals of spectrometer detectors D24 through D30 measured in the first experiment with medium attenuation as an example, the curve shapes obtained in the other measurement series are all similar. The results can be summarized as follows. First, after correction for output pulse energy, the sum over all detector signals is nearly wavelength independent $<408.2 \mathrm{~nm}$. No features are discernible that can be correlated with the photon-insensitive areas between the detectors. However, shadowing near the detector-row edges leads to reduced spectrometer sensitivity in channels D30 and D31. Second, the fraction of total available signal exhibits a
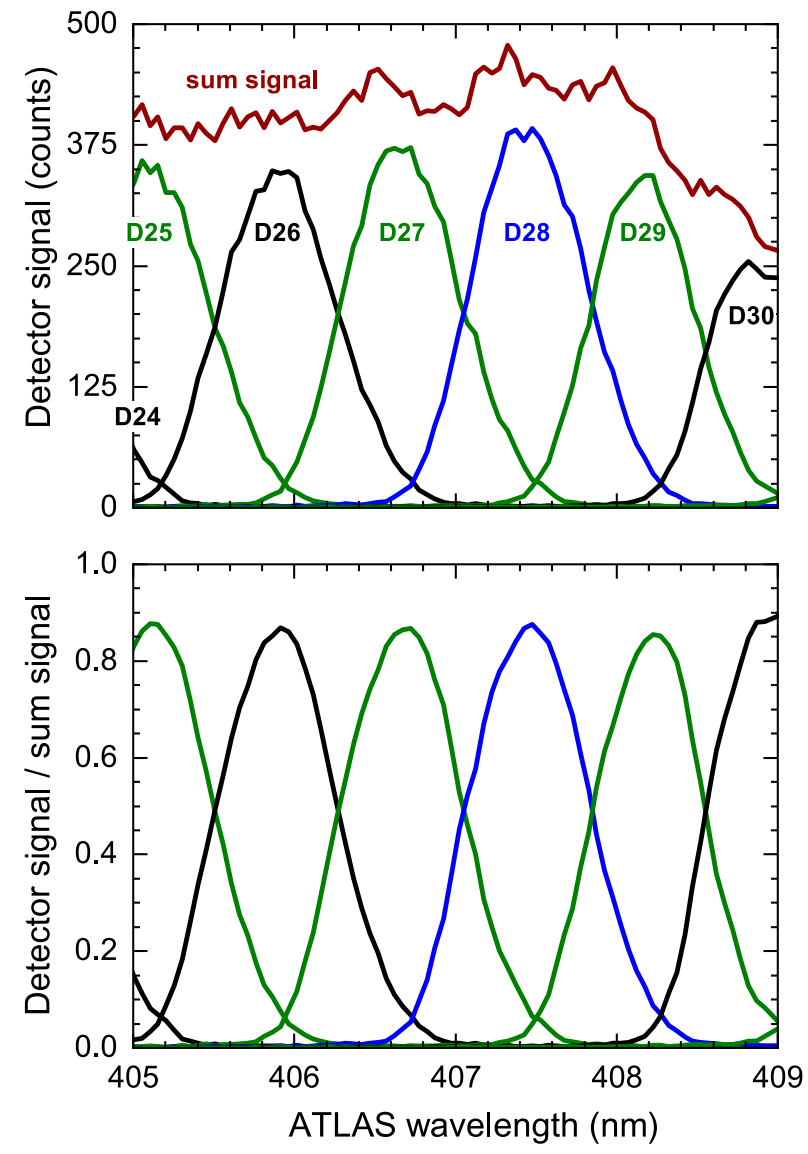

FIG. 1. Characterization of the water spectrometer with the ATLAS tunable laser. (top) Signals of water spectrometer detectors D24-D30 in the range of the Raman spectrum of water vapor. The spectrometer was operated with standard settings $(397 \mathrm{~nm}$ center wavelength, 850 V PMT voltage, discriminator level 8). Signals are corrected for differences in ATLAS output energy; the sum signal is shown for comparison. The wavelength scan was performed with a step width of $0.05 \mathrm{~nm}$. (bottom) Fraction of total available signal per detector channel as function of ATLAS emission wavelength.

virtually identical (albeit shifted) dependence on wavelength for all detectors. The contribution of the water-vapor Raman spectrum to signal D28 is maximum, but also significant to those of the neighboring detectors D27 and D29. D28 peak sensitivity of about $87 \%$ is confirmed by all measurement series, and matches the experimental value determined previously with the operational RAMSES instrument in Lindenberg (spectrometer CWL scans under stable atmospheric conditions with a narrow-band water-vapor interference filter inserted in front of the fiber coupler). Finally, with regard to minimal cross talk with the adjacent detectors (D27, D29), the standard spectrometer CWL of $397.0 \mathrm{~nm}$ is a reasonable choice.

Convolution of the detector spectral responses with the water-vapor Raman spectrum (Avila et al. 1999) yields the effective relative Raman backscattering cross section of each channel. The results are shown in Fig. 2. About 81.6\% 

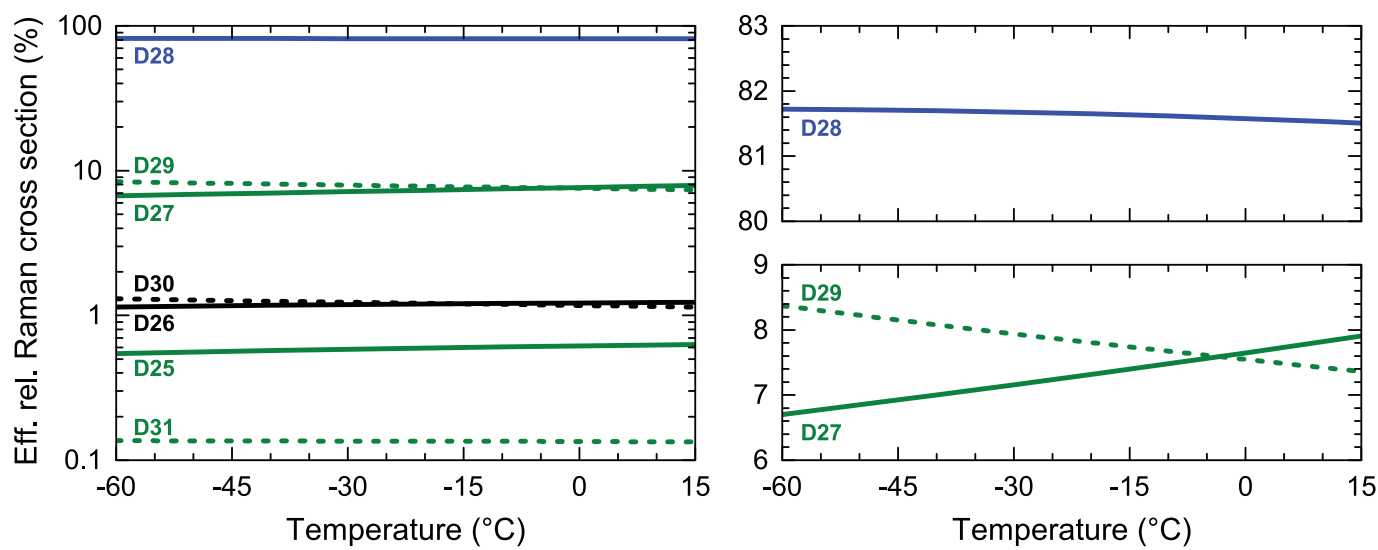

FIG. 2. Effective relative water-vapor Raman backscattering cross section as function of temperature for (left) detector channels D25-D31 (logarithmic scale), (top right) detector channel D28 used for the water-content measurements with RAMSES, and (bottom right) for the neighboring detection channels D27 and D29.

of Raman backscattering by a water molecule in the vapor phase is collected by detector D28. D28 is used for the water-content measurement, so it is an important observation that its temperature dependence is small. Roughly $15 \%$ of inelastic scattering is lost to the flanking channels while the insignificant remainder is distributed between the detectors farther out.

\section{3) EFFECTIVE ABSOLUTE DIFFERENTIAL RAMAN BACKSCATTERING CROSS SECTION OF WATER VAPOR}

The ATLAS measurements together with the publications by Penney and Lapp (1976) and Avila et al. (1999) allow one to calculate the absolute value of $d \sigma_{\text {vap }}^{\text {eff }}(\pi) / d \Omega$. Penney and Lapp (1976) measured the absolute Ramanscattering cross section of water vapor at wavelengths of 488 and $514 \mathrm{~nm}$. It is reported that the spectrometer function was nearly rectangular in shape with an FWHM of 31 $\mathrm{cm}^{-1}$ (spanning the $\nu_{1} Q$ branch). Under the assumption that the $\nu_{1} Q$ branch was centered in the spectrometer bandwidth, their results correspond to a spectral width of about $514 \mathrm{pm}$ in the water-vapor Raman spectrum (407.125-407.639 $\mathrm{nm}$ ) and an absolute cross section of $6.35 \times 10^{-34} \mathrm{~m}^{2} \mathrm{sr}^{-1}$ when excited with the RAMSES laser wavelength of $354.72 \mathrm{~nm}$. The measurement error is about $10 \%$. Convolution of the RAMSES spectrometer function with the spectral data of Avila et al. (1999) yield for the same UV wavelength interval a cross section slightly larger than $6.24 \times 10^{-34} \mathrm{~m}^{2} \mathrm{sr}^{-1}$ for temperatures $<0{ }^{\circ} \mathrm{C}$, which is only $2 \%$ smaller than the value deduced from Penney and Lapp (1976). An artificial widening of the slit by \pm 50 or \pm 150 pm gives only slightly higher results. Considering the experimental unknowns, the agreement can be considered as excellent. For detector channel D28 used for the water-content measurements, it follows

$$
d \sigma_{\text {vap }}^{\text {eff }}(\pi) / d \Omega=(5.2 \pm 0.6) \times 10^{-34} \mathrm{~m}^{2} \mathrm{sr}^{-1}
$$

\section{b. Relative Raman cross section for droplets: $\eta_{\mathrm{liq}}$}

The relative Raman cross section of droplets has been the subject of publications before (Veselovskii et al. 2002; Plakhotnik and Reichardt 2018); however, these earlier results are not adequate for liquid-water clouds with predominantly small droplets, because the problem of structural resonances was not sufficiently investigated. Structural resonances, i.e., enhancement of backscattering for droplet diameters resonating with the laser or Raman wavelengths, determine the magnitude of $\eta_{\text {liq }}$ to a substantial extent, and the effect of the resonances depends in turn on several factors.

First, pulse duration and light absorption. Pulsed excitation may not be sufficiently long to reach a steady-state value which is necessary for strong resonances. In our calculations, the pulse effect was accounted for by an effective absorption coefficient, which is 3.3 times larger than the natural absorption of liquid water at $355 \mathrm{~nm}$, and 5.6 times larger at $403.75 \mathrm{~nm}$.

Second, computational resolution. In small droplets, the resonances are relatively broad, and therefore, the enhancement of Raman backscattering is observed for extended diameter ranges. To obtain a satisfactory representation of the resonance bands, the computations were carried out with high resolution for droplets $<55 \mu \mathrm{m}$ [section $3 \mathrm{~b}(3)$ ].

Third, the droplet size distribution. The effect is discussed in section $3 b(3)$, where $\eta_{\text {liq }}$ values for different cloud types and drizzle are provided. In principle, the finite width of the scattered Raman spectrum affects $\eta_{\text {liq }}$ as well. However, this effect is only significant if the relative width of the cloud size distribution is narrower than the relative width of the Raman band, i.e., narrower than about $2 \%$.

Fourth, deviation from the perfect spherical shape. When cloud droplets reach a critical diameter and start to fall with an appreciable fall speed, aerodynamic forces act on the drop and cause shape deformations and oscillations. As a result, the degeneracy of many structural resonances is lifted and the narrow resonances turn into wider bands. The radiative loss of these resonances may increase too, and the coupling 
between the incident wave and the resonances becomes less efficient than in the case of an exact sphere. These factors tend to decrease the significance of the resonance for nonspherical particles, although theoretically the resonances do not cease to exist. The effect of shape distortions on $\eta_{\text {liq }}$ is investigated in the following sections $3 b(1)$ and $3 b(2)$ using a spheroidal particle model.

\section{1) RAMAN SCATTERING BY SPHEROIDS}

The electromagnetic field inside a spheroid is calculated with a freely available code for computing $\mathrm{T}$ matrices (Somerville et al. 2016), optimized for speed and adopted for multiprecision toolbox ADVANPIX (calculations for particles larger than about $4-5 \mu$ m require quadruple accuracy). The validity of the $\mathrm{T}$-matrix method for the field computation is discussed by Auguié et al. (2016). The inner field is then used for determining the Raman differential backscattering cross section as described in Plakhotnik and Reichardt (2018).

It is assumed that the exciting laser pulse $(355 \mathrm{~nm})$ is linearly polarized, the spheroids are randomly oriented, and the lidar receiver is polarization insensitive. Refractive indices of liquid water (Harvey et al. 1998) are used consistently through all computations. Given that the difference of the refractive indices for water and ice is about $3 \%$, the results are very similar for both except for the exact position of narrow structural resonances. Such resonances depend on the geometrical shape of the particles much more than on the small variation of the refractive index. For a perfect sphere the off-resonance value of $\eta$ changes less than $10 \%$ if the refractive index of ice is used instead of liquid water.

Once maximum dimension and aspect ratio of the spheroid were selected, the computations were performed for the 2 polarization planes of the incident wave and 19 angles $(0 \leq \gamma \leq$ $\pi / 2)$ between the direction of the particle's symmetry axis ( $c$ axis) and the direction of the wave vector. Finally, results were rotationally and polarization averaged. Because the calculations are extremely time consuming and numerically challenging, the largest size parameter for which $\eta_{\text {liq }}$ could be obtained was about 75 .

Figure 3 highlights the results obtained for randomly oriented oblate and prolate spheroids (aspect ratio of $1 / 3$ and 3 , respectively) with maximum dimensions around $8.25 \mu \mathrm{m}$. For comparison, smoothed $\eta_{\text {liq }}$ values of spheres are also shown. Relative Raman scattering tends to decrease with deviation from the spherical shape. The effect is much more pronounced for prolate than for oblate spheroids. Note also that the resonances are observed only for the oblate spheroid. Qualitatively this can be understood by considering a ray propagating nearly perpendicular to the axis of rotation. Such a ray will be confined in a small region near the equator in the case of the oblate spheroid but will drift away in the prolate spheroid. With $\gamma$, values of $\eta_{\text {liq }}(\gamma)$ generally increase and the resonances are observed for aspect ratios significantly larger, or smaller, than unity, but the resonance strengths of prolate spheroids are much more susceptible to the deviation from an ideal sphere and appear only at higher $\gamma$. For aspect ratios of

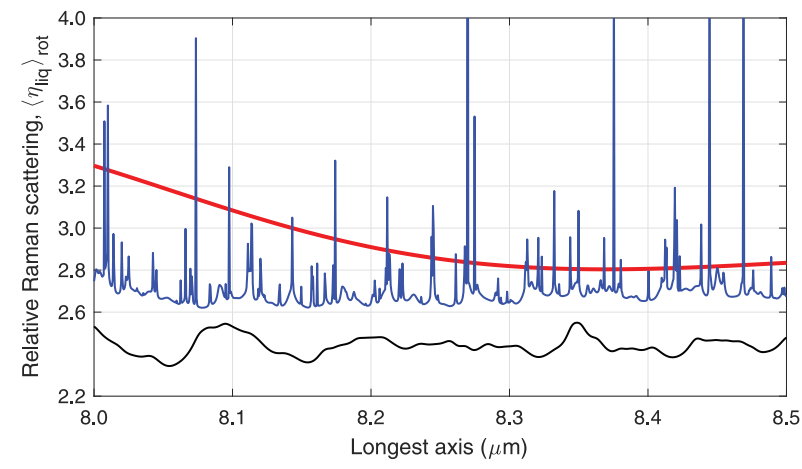

FIG. 3. Rotationally averaged relative Raman backscattering cross sections of an oblate spheroid (aspect ratio of $1 / 3$, blue curve) and prolate spheroid (aspect ratio of 3, black curve). For comparison, the red curve shows the relative Raman backscattering cross section of a sphere averaged over a Gaussian size distribution with a relative standard deviation of $2.5 \%$.

$1 / 3$ and 3 , one finds off-resonance $\eta_{\text {liq }}$ values of $\sim 2.65$ and $\sim 2.4$ and mean $\eta_{\text {liq }}$ values of 2.71 and 2.44 , respectively. For maximum dimensions between 8.25 and $8.5 \mu \mathrm{m}$, the mean $\eta_{\text {liq }}$ of spheres is $\sim 2.8$.

\section{2) RAMAN SCATTERING BY OSCILLATING DROPLETS}

Depolarization measurements of clouds and precipitation suggest that shape oscillations reveal themselves only in raindrops whose sizes are currently beyond our computing power (Szakáll et al. 2010). Nevertheless, a qualitative understanding of the effect can be gained by studying droplets of smaller diameter, between 7.82 and $7.92 \mu \mathrm{m}$ and between 8.31 and $8.41 \mu \mathrm{m}$ in our case. Only the lowest-frequency term of the classical solution of an oscillating droplet was considered (Tsamopoulos and Brown 1983), the maximum amplitude of the oscillation was $2.5 \%$ of the sphere size, the amplitude increment was $0.25 \%$. The oscillating spheroids were randomly oriented, as in the previous computations $\eta_{\text {liq }}$ values were obtained for 19 different scattering geometries for each asphericity. Finally, the results were rotationally and temporally averaged.

Figure 4 illustrates our findings. Effective Raman backscattering of an oscillating droplet shows a generally smoother dependence on diameter than a sphere of same mass. Evidently, broader features of $\eta_{\text {liq }}$ are averaged out by the rotation and vibration as the black lines have no trend within the simulated ranges. The number of resonances observed depends on the amplitude increment, for continuous deformation there would be no sharp spikes at specific values of the diameter.

Averaged over the size range $8.31-8.41 \mu \mathrm{m}$, mean $\eta_{\text {liq }}$ is the same for oscillating and static spheres $\left(\bar{\eta}_{\text {liq }}=2.7\right)$, but this is not generally the case. The size range 7.82-7.92 $\mu \mathrm{m}$, for example, encompasses a sphere resonance which is not only exceedingly strong $\left(\eta_{\text {liq }}=3800\right.$ at $\left.7.873 \mu \mathrm{m}\right)$ but also wide enough to affect the range-averaged relative Raman scattering $\left(\bar{\eta}_{\text {liq }}=3.9\right)$. Our calculations show that this resonance is extremely sensitive to shape distortions which reduce its 

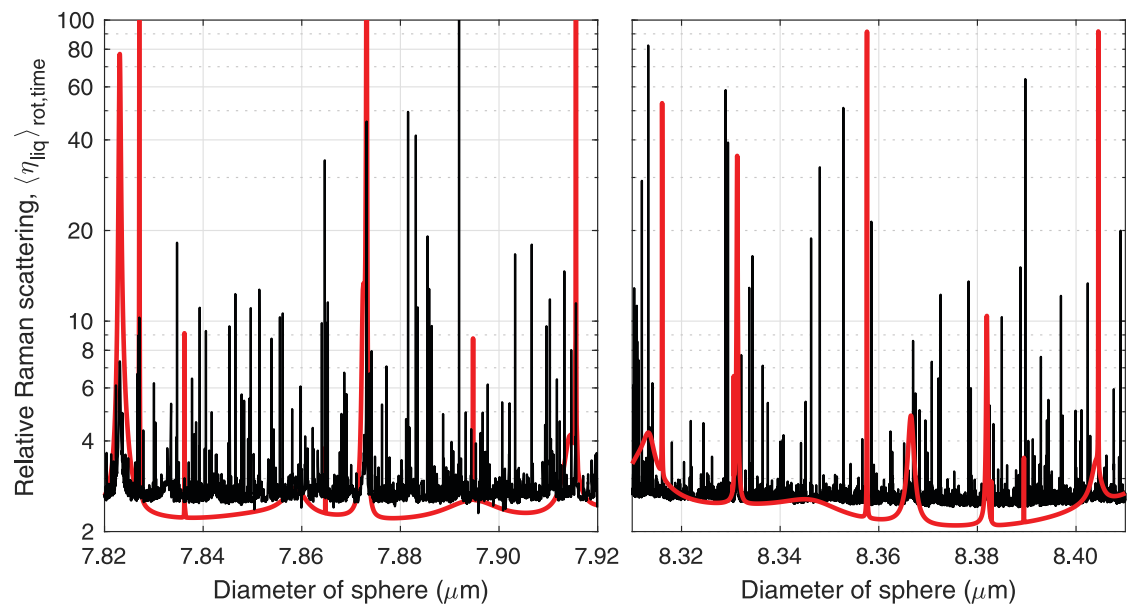

FIG. 4. Rotationally and temporally averaged relative Raman backscattering cross section of an oscillating sphere (black curve) for two diameter ranges around $8 \mu \mathrm{m}$. The amplitude of the oscillation is $2.5 \%$ of the sphere size. The increment of the diameter is $2 \times 10^{-5} \mu \mathrm{m}$. The red line shows scattering of the volume-equivalent sphere at equilibrium.

contribution to Raman backscattering substantially $\left(\bar{\eta}_{\text {liq }}=2.9\right)$. Summarizing, the results suggest that oscillations tend to reduce the effect of resonances on $\eta_{\text {liq. }}$. In oscillating drizzle and raindrops the effect can be expected to be further limited, because the width of structural resonances decreases with size and higher-frequency terms of the oscillations will likely reduce the resonance strength. With this caveat in mind, we will use the off-resonance $\eta_{\text {liq }}$ values of droplets for large atmospheric drops [section $3 b(3)]$.

\section{3) SPECIFIC $\eta_{\text {liq }}$ VALUES}

As shown in the preceding section, structural resonances increase the value of the effective Raman backscattering cross

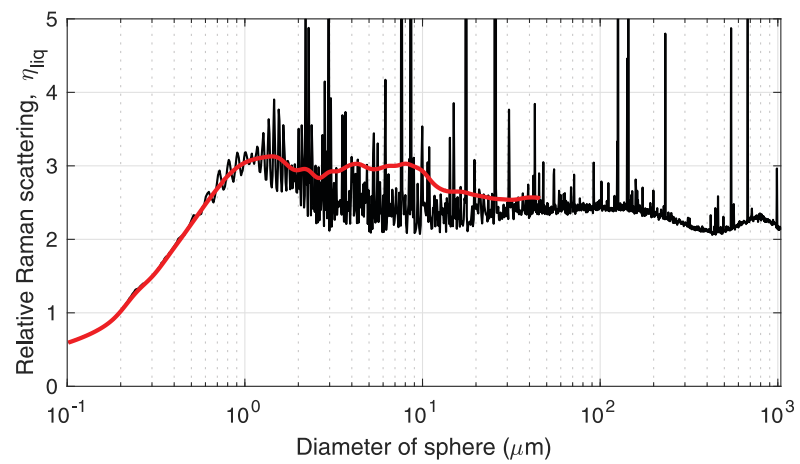

FIG. 5. Low-resolution calculations from Plakhotnik and Reichardt (2018) (black curve) and moving average of the high-resolution data (red curve). The moving average is obtained assuming a normal distribution of the diameters within an ensemble of spheres with a standard deviation of $10 \%$ of the corresponding mean value. The relative increment is $5 \times 10^{-5}$ from 1 to $3 \mu \mathrm{m}, 5 \times 10^{-6}$ from 3 to $5 \mu \mathrm{m}, 2 \times 10^{-6}$ from 5 to $11 \mu \mathrm{m}, 5 \times 10^{-7}$ from 11 to $18 \mu \mathrm{m}$, $5 \times 10^{-8}$ from 18 to $22 \mu \mathrm{m}, 2 \times 10^{-8}$ from 22 to $50 \mu \mathrm{m}$, and $1 \times$ $10^{-8}$ above $50 \mu \mathrm{m}$. Note that the tenfold increase in the resolution at a diameter of $18 \mu \mathrm{m}$ does not produce appreciable change in the averaged values of the cross section. section of nonoscillating spheres even if averaged over a size range. For this reason, it is important to use resonance-resolving data for calculation of $\eta_{\text {liq }}$ of liquid-water clouds. Previously, we published an $\eta_{\text {liq }}$ dataset that extends to droplet sizes large enough to be applicable to hydrometeors such as drizzle (Plakhotnik and Reichardt 2018), but its resolution is insufficient to properly account for resonances in liquid-water clouds with smaller effective radii which made a rerun at higher resolution in the size range of cloud droplets necessary. Figure 5 compares high- and low-resolution $\eta_{\text {liq }}$ data. Because the large number of resonances could not be resolved graphically, the high-resolution data are smoothed for illustrative purposes. Because of the resonances, $\eta_{\text {liq }}$ values increase from nonresonant levels by, for instance, about $40 \%$ for spheres with diameters of $3.5 \mu \mathrm{m}\left(\eta_{\text {liq }}=2.95\right), 23 \%$ at $20 \mu \mathrm{m}\left(\eta_{\text {liq }}=\right.$ $2.60)$, and $14 \%$ at $45 \mu \mathrm{m}\left(\eta_{\text {liq }}=2.56\right)$.

The high-resolution data were used to determine the relative Raman backscattering cross sections of standardized liquidwater clouds with different droplet size distributions (Plass and Kattawar 1971; Deirmendjian 1975; Shettle 1990). It is found that $\eta_{\text {liq }}$ does not vary with cloud type significantly, values calculated for cumulus, stratocumulus, stratus, altostratus, and nimbostratus range between 2.58 and 2.74 with an average of

$$
\eta_{\text {liq }}=2.63 \pm 0.07 \quad(\text { cloud }) .
$$

Finally, in view of the discussion in the previous section $3 b(2)$, a good estimate for the effective relative Raman backscattering of drizzle and light precipitation is the off-resonance $\eta_{\text {liq }}$ value of large spheres (Fig. 5), which is

$$
\eta_{\text {liq }}=2.2 \pm 0.2 \quad \text { (drizzle, } \text { rain) }
$$

\section{c. Relative Raman cross section for ice particles: $\eta_{\mathrm{ice}}$}

The determination of $\eta_{\text {ice }}$ is a difficult task because, in contrast to $\eta_{\text {liq, }}$, the nonspheroidal shape of the ice particles 
makes a direct calculation impossible. Furthermore, the modeling of the inelastic backscatter of microparticles, which was considered as an alternative because of previous encouraging studies (Weigel et al. 2006), has proven to be complex and error prone. In addition, it has not yet been possible to establish a relationship between the model results and Raman backscattering by bulk ice. For these reasons, an experimental approach to the estimation of $\eta_{\text {ice }}$ is pursued instead. It is based on the idea that $\eta_{\text {ice }}$ can be obtained from a RAMSES measurement of a melting layer if it is ensured that the total number of water molecules in the condensed phases does not change during the phase transition.

To make sure that this requirement is met, several criteria were defined for the selection of a suitable measurement:

1) A frontal system should be observed. Then the assumption is justified that the whole cloud migrates and melts through the $0^{\circ} \mathrm{C}$ level (continuity is guaranteed) and not only some ice particles precipitate from an otherwise stable stratified ice cloud.

2) The optical properties must support the findings (depolarization ratio increases with height, backscatter coefficient outside the lidar dark band relatively constant).

3) The relative humidity with respect to ice or water should be close to $100 \%$, so that the loss of the liquid phase to the vapor phase can be neglected.

4) Only cases with LWC profiles constant in heights below the melting layer should be selected as a further indication of negligible losses to the gas phase.

5) The measurement must yield with good statistical error LWC and IWC in the ice cloud over a sufficiently large penetration depth (optical depth $<2$ ).

6) The separation of the phases in liquid water below and water ice above the melting layer (no mixed-phase cloud) should be complete and unambiguous.

7) The spectral properties (Raman spectra) must support the findings.

All requirements are met by the exceptional RAMSES measurement on 17 June 2015.

\section{EXPERIMENTAL DETERMINATION OF $\eta_{\text {ice }}$}

On 17 June 2015, RAMSES was operated continuously. A frontal system entered the RAMSES field of view around noon. The bottom edge of the cirrus was descending, by the time the spectrometers were activated after night fall around 2000 UTC, it had almost reached the $0^{\circ} \mathrm{C}$ level at $3 \mathrm{~km}$. First melting was observed $30 \mathrm{~min}$ later, but a dry air layer at $2 \mathrm{~km}$ blocked the hydrometeors from falling further down. It took until 2200 UTC to saturate the air, and precipitation developed unhindered thereafter. RAMSES was finally shut down automatically at 2320 UTC because of rain.

Figure 6 presents the lidar profiles of the RAMSES measurement during 2202-2222 UTC. Water-vapor Raman scattering $\beta_{\mathrm{vap}}^{\mathrm{R}}$, and thus the number density of water molecules in the gas phase, is remarkably height independent between 2.7 and $3.2 \mathrm{~km}$, which means that the key requirement of negligible water losses to the vapor phase is fulfilled. Condensed- water Raman scattering $\beta_{\text {con }}^{\mathrm{R}}$ is equally independent of height, particularly between $\sim 2.9$ and $3.1 \mathrm{~km}$. Raman backscatter coefficients $\beta_{\text {ice }}^{\mathrm{R}}$ and $\beta_{\text {liq }}^{\mathrm{R}}$ indicate a smooth transition from ice to liquid water with decreasing height, with the $50 \%$ point at $3 \mathrm{~km}$ close to the $0^{\circ} \mathrm{C}$ level. At this altitude, a minimum in $\beta_{\text {par }}$ (the socalled lidar dark band, a characteristic feature of a melting layer; see Di Girolamo et al. 2012, and references therein) and a profound change in the elastic optical particle properties are observed, underpinning the phase transition. Analysis of the cloud Raman spectra confirms pure liquid water below $2.8 \mathrm{~km}$ and ice above $3.2 \mathrm{~km}$, and a mixture in between. In summary, given the experimental evidence it is justified to consider the number of condensed water molecules, $n_{\text {con }}$, a conserved quantity in the height range around the $50 \%$ point.

To determine $\eta_{\text {ice }}$, three different $\eta_{\text {liq }}$ values are chosen that are representative of large cloud drops [Eq. (15), section $3 \mathrm{~b}(3)]$. Then $\eta_{\text {ice }}$ is varied until $n_{\text {con }}$ is height independent. Two different altitude ranges are considered, a narrow range centered around the $50 \%$ point and a broad range covering the entire melting layer, to study the robustness of the results. For the narrow height interval $(2.90-3.05 \mathrm{~km})$, the analysis yields fitting pairs of $\eta_{\text {liq }}$ and $\eta_{\text {ice }}$ of 2.0 and 1.62, 2.2 and 1.80, and 2.4 and 1.96, for the broad height interval $(2.87-3.23 \mathrm{~km})$ one finds the pairs 2.0 and 1.90, 2.2 and 2.10, and 2.4 and 2.30.

In all cases, $\eta_{\text {ice }}<\eta_{\text {liq }}$ is found, which is in general agreement with the computation results presented for spheroids in section $3 b(1)$. Although the model spheroids are comparatively small (maximum dimension of about $8 \mu \mathrm{m}$ ), the investigations still suggest that deviations from the spherical shape lead to a reduction of $\eta_{\text {ice }}$ values, so the finding is therefore to be expected. Incidentally, $\eta_{\text {ice }} / \eta_{\text {liq }}$ of the narrow and broad interval are about 0.82 and 0.95 , respectively, which is similar to the theoretical ratios of prolate and oblate spheroids to spheres [0.86 and 0.96 , section $3 b(1)]$. Given the differences in shapes and sizes, this similarity between model and natural cloud may be regarded as coincidental, but still it is an interesting observation that may hint at some optical resemblance, perhaps that the geometricaloptics limit has been reached in the artificial particles and that therefore size does not play a significant role.

In summary, analysis of the RAMSES measurement on 17 June 2015 yields

$$
\eta_{\text {ice }}=1.9 \pm 0.3
$$

Note that the systematic uncertainty in $\eta_{\text {ice }}$ is doubled by considering both height intervals. Future analyses of similar measurement cases may reduce the systematic error.

\section{Measurement examples}

The examples presented in this section are intended to showcase the measurement capability of a spectrometric water Raman lidar such as RAMSES. The investigation of scientific issues is reserved for future publications.

\section{a. Supercooled cloud}

In the night of 19-20 April 2015 RAMSES observed a dynamic cloud system between 4 and $10 \mathrm{~km}$. Measurement 

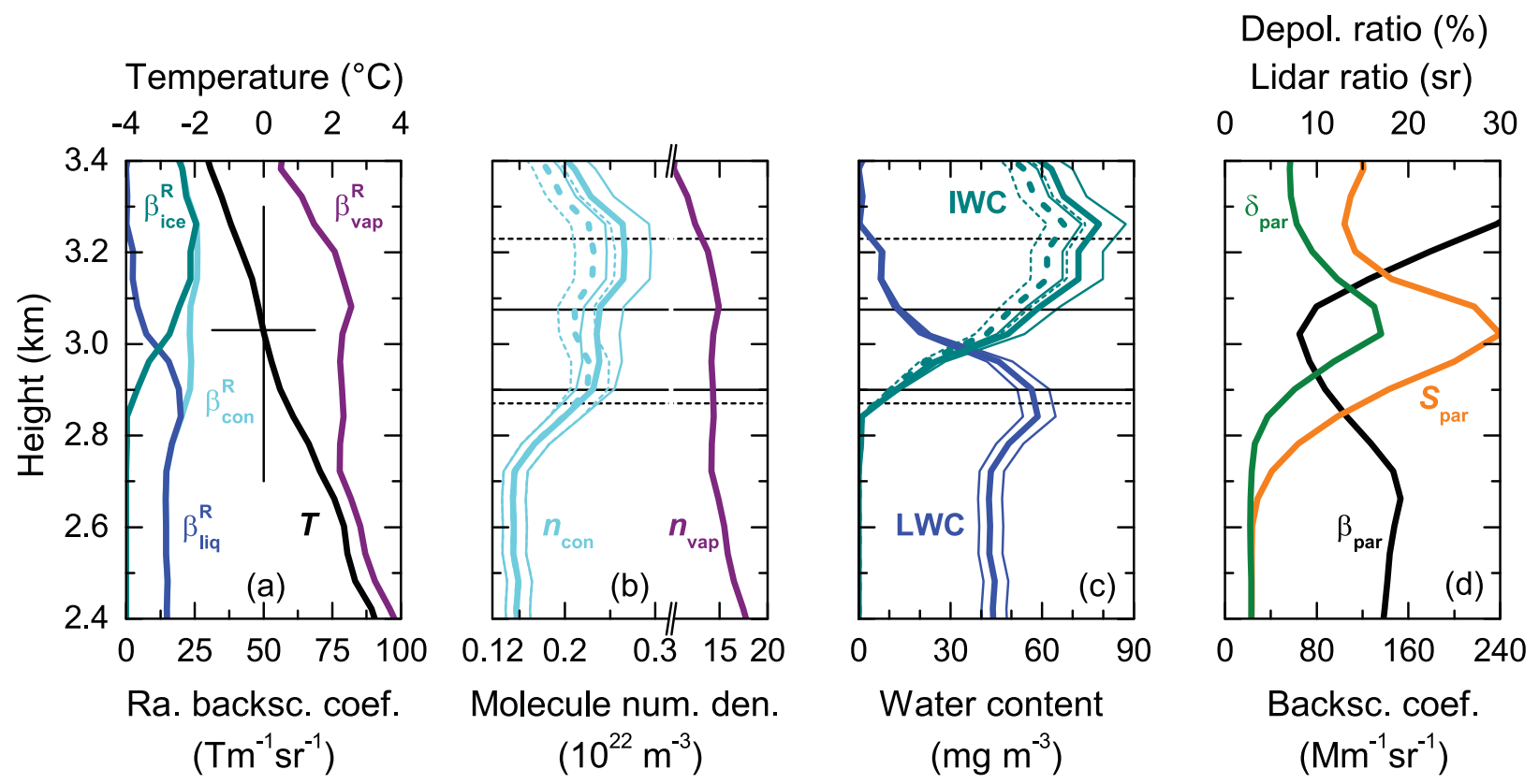

FIG. 6. Estimation of $\eta_{\text {ice }}$ from the measurement of a melting layer at 2212 UTC 17 Jun 2015. Profiles of (a) Raman backscatter coefficients of water molecules in the three phases $\left(\beta_{\mathrm{vap}}^{\mathrm{R}}, \beta_{\text {liq }}^{\mathrm{R}}, \beta_{\text {ice }}^{\mathrm{R}} ; \beta_{\mathrm{con}}^{\mathrm{R}}=\beta_{\text {liq }}^{\mathrm{R}}+\beta_{\text {ice }}^{\mathrm{R}}\right)$, and temperature $(T)$, (b) water molecule number density of the condensed phase $\left(n_{\text {con }}\right)$ and the vapor phase ( $n_{\text {vap }}$, note the scale break), (c) ice water content (IWC) and liquid water content (LWC), and (d) particle backscatter coefficient $\left(\beta_{\text {par }}\right)$, depolarization ratio $\left(\delta_{\text {par }}\right)$, and lidar ratio $\left(S_{\text {par }}\right)$. Profiles in (b) and (c) illustrate the effect of selecting different pairs of $\eta_{\text {liq }}$ and $\eta_{\text {ice }}$ on $n_{\text {con }}$ and IWC and LWC, respectively. To determine $\eta_{\text {ice, }}$, three different $\eta_{\text {liq }}$ values (2.0, 2.2, 2.4) are chosen that are representative of large cloud drops and precipitation (Fig. 5). Then $\eta_{\text {ice }}$ is varied until $n_{\text {con }}$ is height independent either in a narrower altitude range centered around the height of equal Raman backscattering by liquid and frozen water (solid curves, solid horizontal lines), or in a broader range covering the entire melting layer (dashed curves, dashed horizontal lines). Also shown in (a) are the $T$ values obtained by interpolating radiosonde data available every $6 \mathrm{~h}$ to the observation time; the $0^{\circ} \mathrm{C}$ level is indicated by thin black lines. Lidar data integration time is $1200 \mathrm{~s}$; the resolution of the raw data is $60 \mathrm{~m}$. Statistical-error bars of the RAMSES measurement have been omitted for clarity.

conditions were favorable: boundary layer clouds were absent, and the aerosol load and associated fluorescence were low. Most cloud occurrences showed the optical signature of cirrus clouds with either randomly oriented (high lidar and depolarization ratios) or horizontally aligned particles (strongly depressed lidar and depolarization ratios). The one exception was a layered cloud around $5 \mathrm{~km}$ that entered the RAMSES field of view at 2020 UTC and showed little variability for the next $2 \mathrm{~h}$.

Figure 7 presents the RAMSES measurement of this cloud at 2100 UTC. Because of the low water content and the relatively high altitude of the cloud, it was necessary to increase the data integration time to $40 \mathrm{~min}$ (twice the standard integration time) and the bin width from 60 to $90 \mathrm{~m}$ in order to obtain cloud Raman spectra with acceptable accuracy. The Raman spectrum of the upper layer of the cloud $(5.0-5.4 \mathrm{~km})$ is shown in Fig. $7 \mathrm{~d}$. Comparison of the measured Raman spectrum with laboratory measurements convoluted with the water-spectrometer response function clearly shows that the cloud upper layer consisted of supercooled droplets. This spectrum is suitable for illustrating some of the difficulties of spectral measurements. First, correction for Raman backscattering by water vapor is a complicated step in the water-content calculation chain. A reference watervapor spectrum is subtracted from the spectrum measurement (section $2 b$ ). At the longer wavelengths where the vapor phase still dominates water inelastic backscattering, the subtraction leads to a significant increase in the statistical errors of the condensed-phase spectral Raman backscatter coefficients, for instance, at $406.5 \mathrm{~nm}$. Another side effect of the overlapping Raman spectra is that the condensed-phase spectrum cannot be obtained around the $Q$ branch of water vapor $(407.5 \mathrm{~nm})$. This does not state a problem for phase determination by band decomposition, but it has to be taken into account when the spectrum is integrated for LWC determination. This is done by extrapolating the measured spectrum $<406 \mathrm{~nm}$ to longer wavelengths utilizing the well-known spectral shape of the liquidwater spectrum. The result is also shown in Fig. 7d. In this case, the extrapolation increases the spectrum integral by about $5 \%$.

The optical particle properties corroborate the spectral analysis (Fig. 7b). The lidar ratio (corrected for multiple scattering) exhibits values around $20 \mathrm{sr}$ and the depolarization ratio is very small at the bottom of the layer and shows a moderate increase with penetration depth, which are both typical features of water clouds. The RAMSES measurement yields temperatures of about $-20^{\circ} \mathrm{C}$ of the supercooled cloud, and a relative humidity with respect to liquid water around saturation (Fig. 7c).

LWC is calculated using the $\eta_{\text {liq }}$ value of clouds [Eq. (14)], maximum LWC is $15 \mathrm{mg} \mathrm{m}^{-3}$ (Fig. 7a). Measurement 

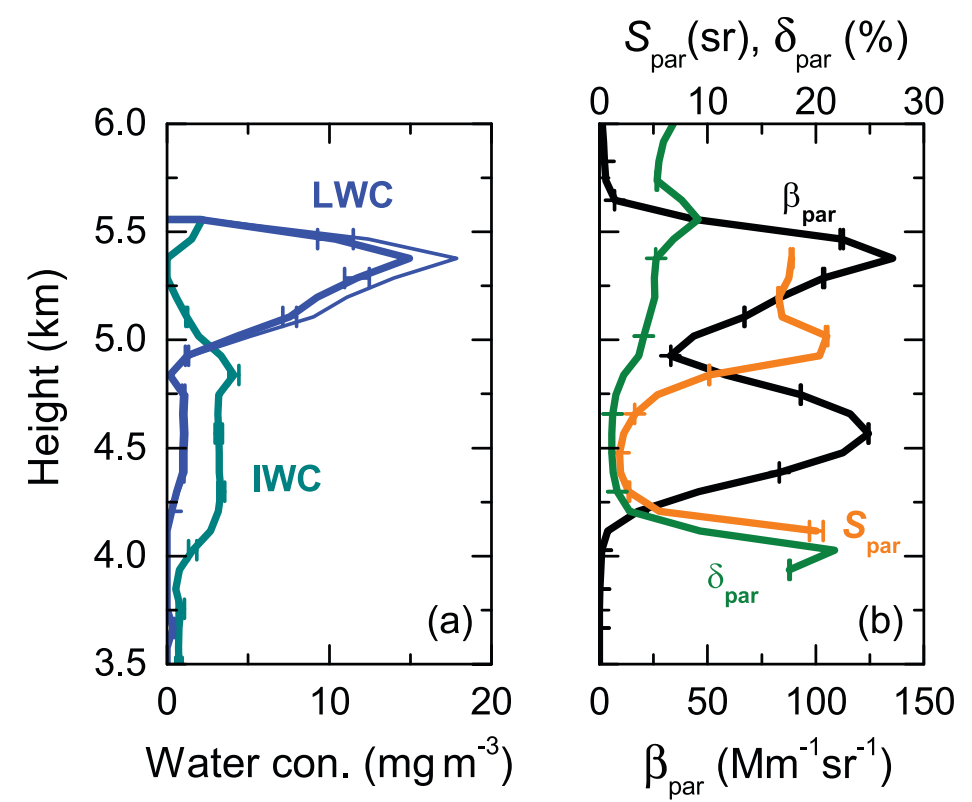

\section{Temperature $\left({ }^{\circ} \mathrm{C}\right)$}
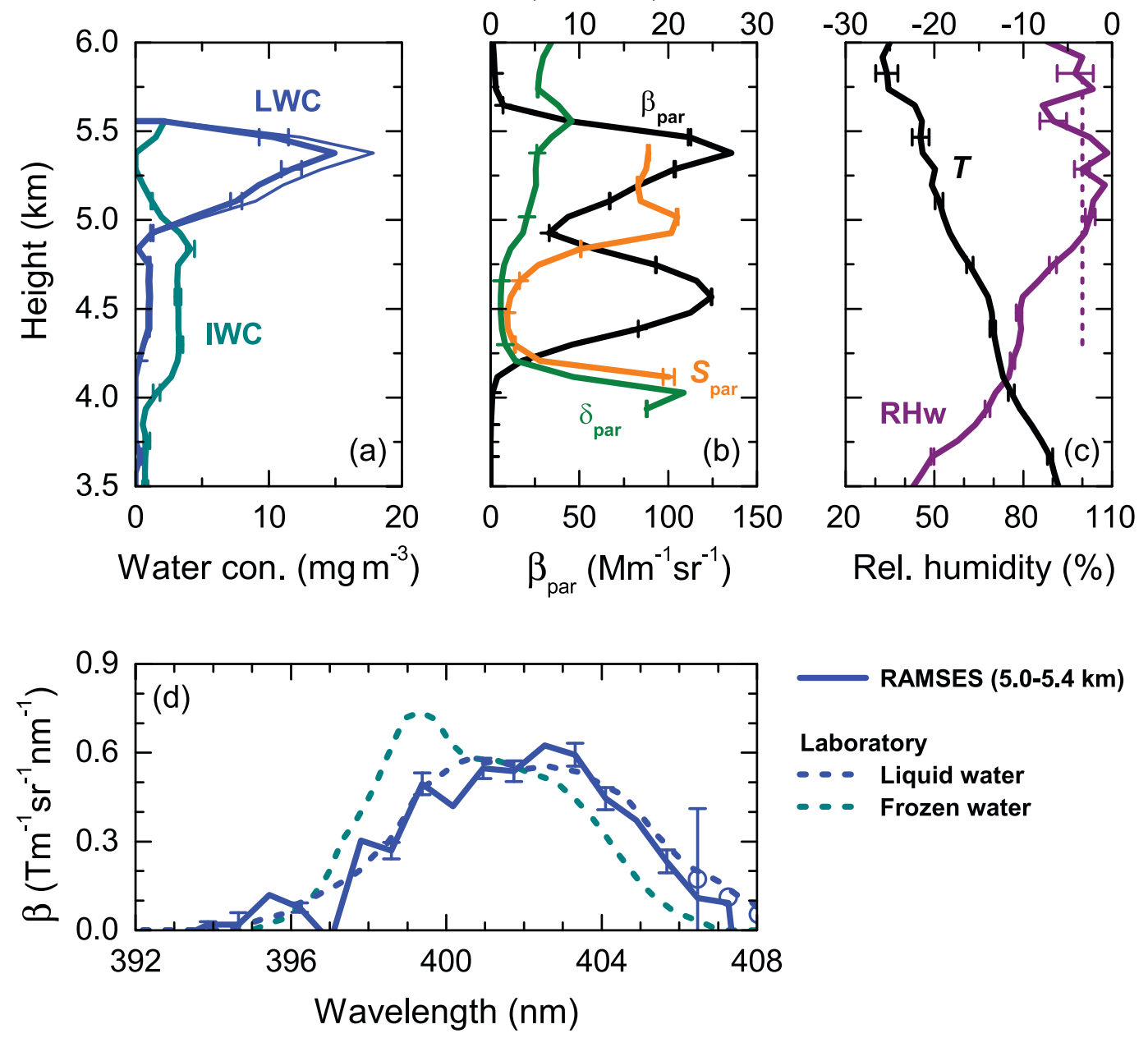

RAMSES (5.0-5.4 km)

Laboratory

-. Liquid water

-. Frozen water

FIG. 7. Measurement of a supercooled liquid-water cloud at 2100 UTC 19 Apr 2015. Profiles of (a) IWC and LWC $\left[\eta_{\text {liq }}=2.63\right.$ (thick curve), $\eta_{\text {liq }}=2.20$ (thin curve) $]$, (b) particle lidar ratio $\left(S_{\text {par }}\right)$, depolarization ratio $\left(\delta_{\text {par }}\right)$, and backscatter coefficient $\left(\beta_{\mathrm{par}}\right)$, and (c) temperature $(T)$ and relative humidity with respect to water (RHw, saturation is indicated by a vertical dashed line). (d) Spectral Raman backscatter coefficients $(\beta)$ of the cloud averaged between 5.0 and $5.4 \mathrm{~km}$. Extrapolated $\beta$ values are marked (circles). Raman spectra of liquid and frozen water as measured in laboratory measurements (Slusher and Derr 1975) are shown for comparison. Lidar data integration time is $2400 \mathrm{~s}$; the resolution of the raw data is $90 \mathrm{~m}$. Signal profiles are smoothed with a sliding-average length of 5 height bins. Bars indicate statistical errors of the RAMSES measurement.

errors are mostly statistical, uncertainties due to the estimated errors in $\eta_{\text {liq }}$ have a negligible effect only. However, selection of an $\eta_{\text {liq }}$ value that is appropriate for the measurement situation is important. For illustration, also the LWC profile is shown for which the large-drop $\eta_{\text {liq }}$ value [Eq. (15)] has been assumed. The latter exhibits LWC values $20 \%$ larger which is more than the random error and thus statistically significant.

Below $5 \mathrm{~km}$, the air is subsaturated with respect to water so cloud droplets cannot survive for long. Water content is low, and the spectrum decomposition indicates predominantly frozen water (not shown). The optical properties are characteristic of horizontally aligned ice particles, with $\delta_{\text {par }}$ and $S_{\text {par }}$ as low as $1 \%$ and 2 sr, respectively. So most likely an ice virga of the supercooled cloud is observed.

\section{b. Melting layer}

In the night of 20-21 December 2015 a massive cloud system passed over the Lindenberg site. RAMSES started operation at 1600 UTC and measured for $13 \mathrm{~h}$ uninterruptedly. Around 2330 UTC the cloud base lowered from 4 to around $3 \mathrm{~km}$ where it intersected the $0^{\circ} \mathrm{C}$ level. Figure 8 visualizes the temporal development of the melting layer for the next $2.5 \mathrm{~h}$. Below $2.4 \mathrm{~km}$, relative humidity with respect to water drops sharply. Virga develops before midnight and around 0100 

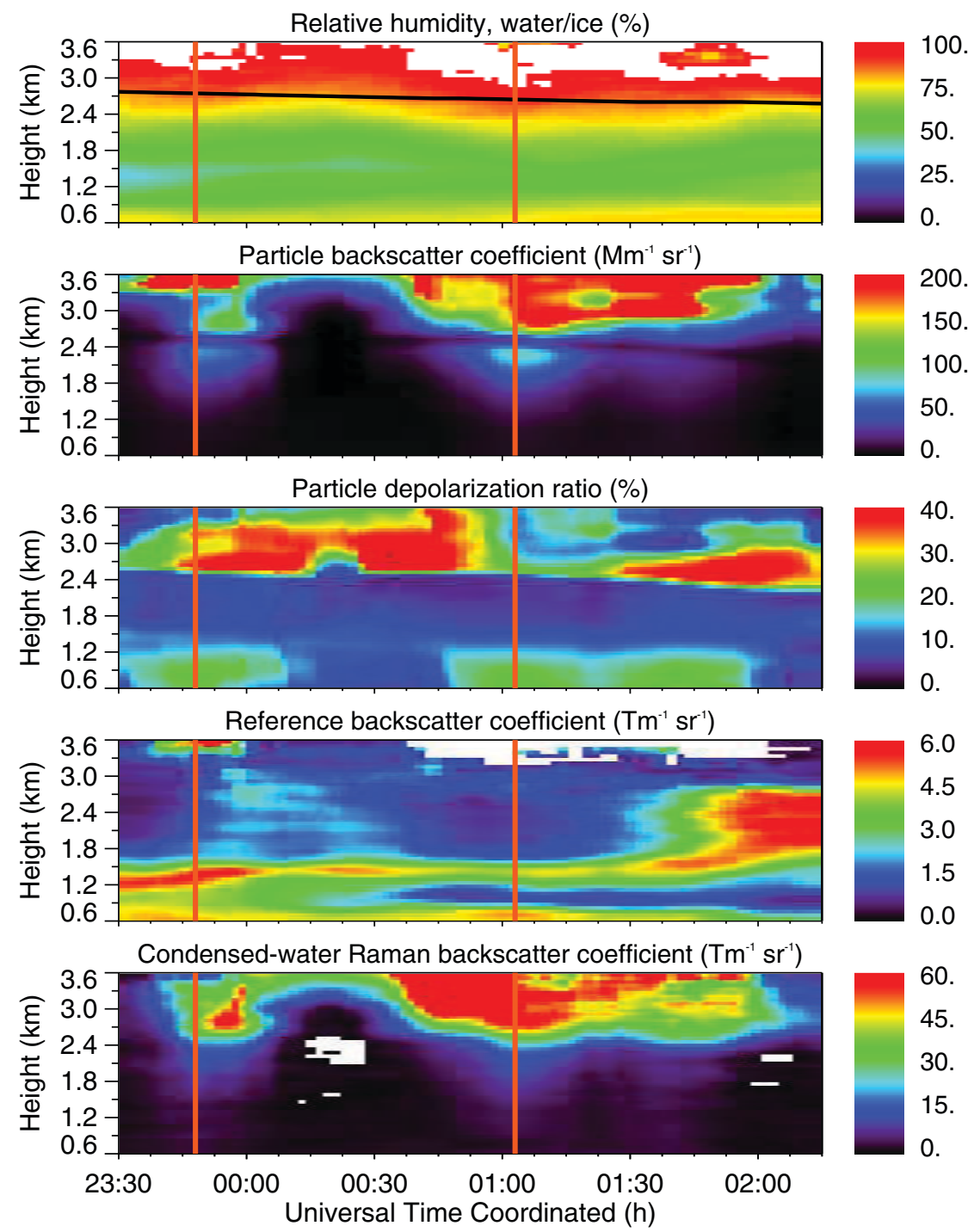

FIG. 8. Temporal evolution of (top to bottom) relative humidity with respect to liquid water and ice for temperatures, respectively, above and below the $0^{\circ} \mathrm{C}$ level (indicated by the black curve), particle backscatter coefficient, particle depolarization ratio, reference backscatter coefficient, and condensed-water Raman backscatter coefficient as measured with RAMSES in the night of 20-21 Dec 2015. Measurements at 2348 and 0103 UTC are analyzed in detail in Fig. 9 (times marked by vertical orange lines). For each profile, $1200 \mathrm{~s}$ of lidar data are integrated; the calculation step width is $120 \mathrm{~s}$. The resolution of the raw data is $60 \mathrm{~m}$; signal profiles are smoothed with a sliding-average length of 3 height bins.

UTC with clearly discernable lidar dark bands. The dark band coincides with a sharp transition in the particle depolarization ratio and a significant change in condensed-water Raman backscattering. An important distinction from the measurement example in section $4 \mathrm{a}$ is that strongly fluorescent aerosols were present. As evidenced by the reference backscatter coefficient, a thin aerosol filament floated around a height of $1.4 \mathrm{~km}$ before widening strongly after 0130 UTC.

Figure 9 shows the RAMSES profiles of two particularly interesting measurement episodes. Whereas IWC values are relatively stable above the $0^{\circ} \mathrm{C}$ level, LWC of the precipitation is decreasing along its fall. The reduction is caused by the low humidity, the rain droplets lose water mass to the vapor phase. This observation is in stark contrast to the measurement case of 17 June 2015 [Fig. 6, section $3 b(1)]$ where no LWC decrease was observed. Interestingly, below $1.7 \mathrm{~km} \delta_{\text {par }}$ starts to rise even though LWC and particle backscatter coefficient continue their decline. A possible explanation is a shift in the droplet size spectrum to larger diameters with distance from the melting layer. In subsaturated air, the smaller droplets evaporate first. Eventually, only the largest drops survive, 
(a) 2348 UTC

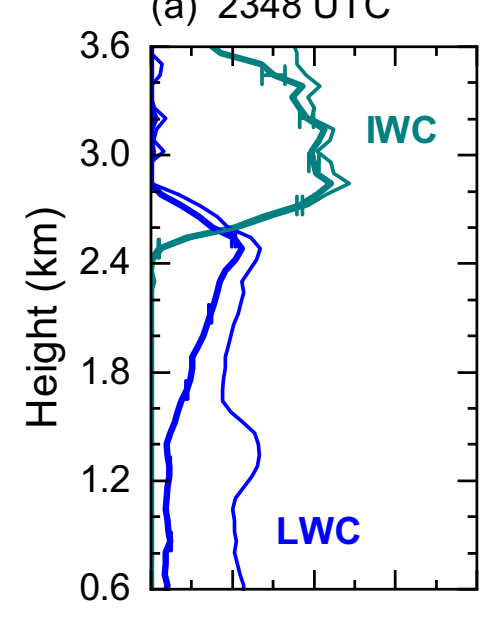

(b) 0103 UTC

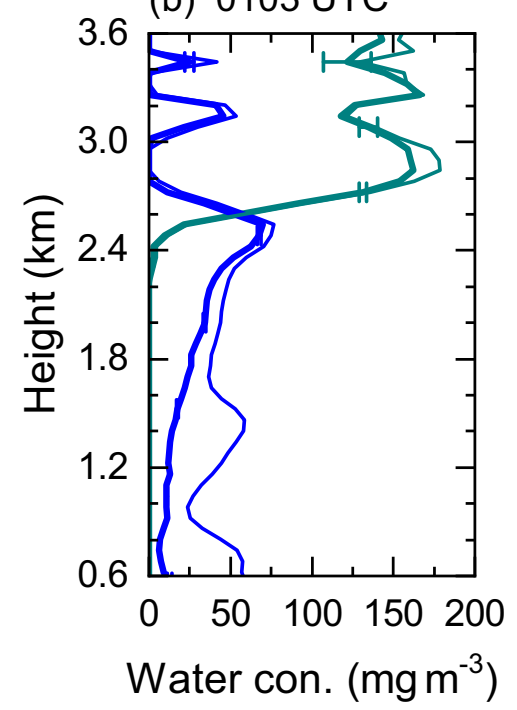

$$
S_{\mathrm{par}}(\mathrm{sr}), \delta_{\mathrm{par}}(\%)
$$
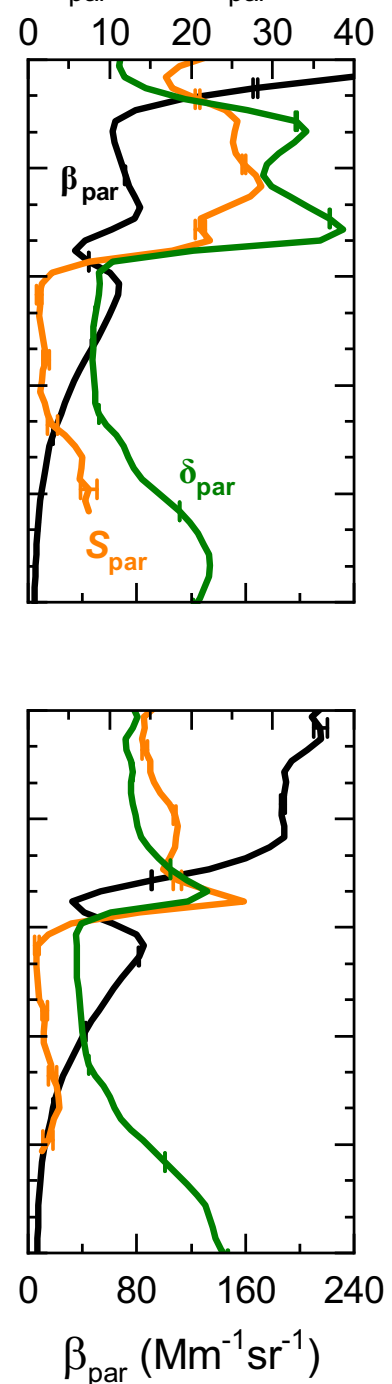

\section{Temperature $\left({ }^{\circ} \mathrm{C}\right)$}

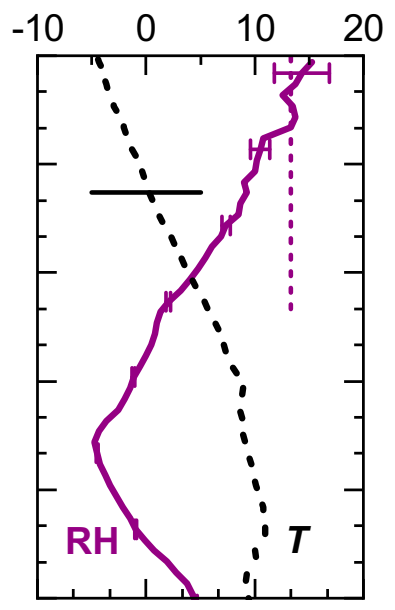

FIG. 9. Measurements of a melting layer in the night of 20-21 Dec 2015. (left) IWC and LWC, (center) particle lidar ratio $\left(S_{\text {par }}\right)$, depolarization ratio $\left(\delta_{\text {par }}\right)$, and backscatter coefficient $\left(\beta_{\text {par }}\right)$, and (right) temperature $(T)$ and relative humidity (RH) observed at (a) 2348 and (b) 0103 UTC. IWC and LWC are presented with (thick curves) and without (thin curves) correction for aerosol fluorescence. Temperature profiles were obtained by interpolating data from radiosondes launched every $6 \mathrm{~h}$ on site; $0^{\circ} \mathrm{C}$ levels are indicated (horizontal black lines). Relative humidity is given with respect to liquid water above $0^{\circ} \mathrm{C}$, and with respect to ice below (saturation marked by vertical dashed violet lines). Lidar data integration time is $1200 \mathrm{~s}$; the resolution of the raw data is $60 \mathrm{~m}$. Signal profiles are smoothed with a sliding-average length of 3 height bins. Bars indicate statistical errors of the lidar measurement.

and these drops tend to oscillate in shape which, in turn, causes $\delta_{\text {par }}$ to increase. As discussed in section $3 b(2)$, shape distortions should not affect $\eta_{\text {liq }}$ significantly, at least when the distortions are small and of spheroidal form, but still the LWC values measured below $1.7 \mathrm{~km}$ should be treated with some caution.

Accurate water-content measurements are only possible if the effect of aerosol fluorescence is thoroughly accounted for. To demonstrate its impact, the results of the analysis of the spectrometer data without fluorescence correction are shown in Fig. 9 as well. In the case of LWC, the fluorescence-induced systematic errors are very large. In fact, the LWC profile is completely determined by fluorescence in both magnitude (systematic errors reach up to several 100\%) and vertical features (cf. the reference backscatter coefficient in Fig. 8). Note that the fluorescence correction removes these features completely (for instance, the apparent maximum in uncorrected LWC around $1.4 \mathrm{~km}$, which is entirely caused by the fluorescence of the aerosol filament). In comparison, the measurement error arising from the uncertainty in $\eta_{\text {liq }}$ (about $9 \%$ ) 
is very low. The same can be said for IWC if aerosol fluorescence is significant in the presence of ice clouds. A good example for such a case was provided previously (Reichardt et al. 2018a); in the measurements presented in Fig. 9 the fluorescence effect on IWC is largest around an altitude of $3.5 \mathrm{~km}$ at 2348 UTC. In relative terms, it is much smaller than the fluorescence errors in LWC. For IWC, the uncertainty in $\eta_{\text {ice }}$ (about 16\%) and the random error remain the dominant error sources. Summarizing, the effect of aerosol fluorescence on the water-content measurements can be significant. Its correction can only be accomplished with spectrometric water lidars, and not with lidar instruments that are equipped with a single condensed-water detection channel only.

Another aspect to be discussed is the effect of statistical errors on the decomposition of the water spectrum. Because of light extinction, the spectral data become increasingly noisy upon penetration of the cloud. The random errors of the individual spectral Raman backscatter coefficients $(\beta)$ add uncertainty to the splitting of the water spectrum and thus phase discrimination becomes more and more unreliable. In fact, ambiguity in the water phase is the dominant cause for the upper bound of the water-content measurement. An instructive example is the RAMSES measurement in Fig. 9b. Here, above $3 \mathrm{~km}$ band decomposition yields two layers of supercooled liquid water. While this could be entirely possible, the optical particle properties do not support this conclusion. $\beta_{\text {par }}, \delta_{\text {par }}$, and $S_{\text {par }}$ all suggest a homogeneous ice cloud. If the cloud really consisted only of ice, IWC would be almost height independent just like these properties. So it can be assumed that the phase determination yielded incorrect results caused by statistical errors. The water-content measurements could be extended to higher altitudes if the phase of the cloud were known from auxiliary data, because then band decomposition would not be necessary and the integrated Raman backscatter coefficient $\beta_{\text {con }}^{\mathrm{R}}$ could be used directly. For instance, if $T<-40^{\circ} \mathrm{C}$, one can exclude the liquid phase (Wettlaufer 1999) and safely calculate IWC. Also, the elastic optical particle properties may clearly indicate a certain water phase, but generally statistical errors limit the range of the water-content measurement.

Incidentally, an interesting outcome of the RAMSES measurement is the decrease in $S_{\text {par }}$ upon phase transition. This is not to be expected, because in liquid-water clouds $S_{\text {par }}$ values are close to $20 \mathrm{sr}$ (see the supercooled cloud in section $4 \mathrm{a}$ ) and so one might assume similar values in drizzle, or rain. Careful tests of the RAMSES analysis software and the multiple-scattering code confirm the low $S_{\text {par }}$ values. High-resolution Mie computations actually reveal similar lidar ratios, but these are restricted to rather small diameter ranges and are thus unlikely to serve as an explanation.

\section{Evaluation of IWC retrieval methods}

In this section standard single-sensor methods for retrieving IWC either from ground-based lidar or cloud radar

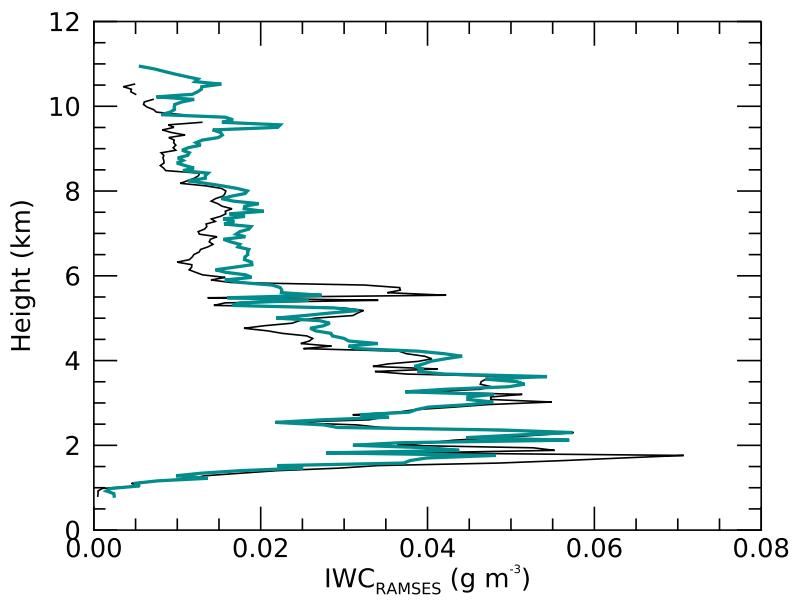

FIG. 10. Mean IWC as function of height, measured with RAMSES between April 2015 and March 2016. The dataset contains about 200 IWC profiles from 21 measurement nights with a total of 2616 quality-assured IWC values. IWC standard deviation is also shown (black curve). Because height and temperature are inversely correlated (mean temperature decreases from $0^{\circ}$ to $-54^{\circ} \mathrm{C}$ between 1 and $11 \mathrm{~km}$ ), depiction of IWC versus temperature would look similar.

observations are evaluated by comparing them with IWC measurements from RAMSES. The IWC retrieval methods involve the use of in situ microphysical observations, from which empirical (power-law) relations between the IWC and the lidar particle extinction coefficient $\left(\alpha_{\text {par }}\right)$ or the IWC and the radar reflectivity factor $(Z)$ are obtained. Investigating the validity of these methods is relevant as they are used both for satellite applications (Heymsfield et al. 2014) and for the continuous application at various ground-based stations across the globe, such as the Cloudnet sites (Illingworth et al. 2007) and the Aerosol, Clouds and Trace Gases Research Infrastructure (ACTRIS) sites (Pappalardo 2018). Methods for retrieving LWC profiles from ground-based remote sensing observations are not examined at this point because the RAMSES dataset of liquid-water clouds is not large enough for statistical analysis.

For the IWC retrieval evaluation, one year of RAMSES measurements have been analyzed for pure-ice and mixedphase clouds, approximately 200 IWC profiles from a total of 21 measurement nights were selected that passed the quality checks. Figure 10 shows the observed IWC mean values as function of height and their standard deviations. As was to be expected, IWC decreases with height above the mean freezing level. IWC values are spread out over a wide range for all altitudes, as indicated by the standard deviation. The number of data points increases with $T$ (decreases with height), in $10^{\circ} \mathrm{C}$ segments starting with $-50^{\circ}$ to $-40^{\circ} \mathrm{C}$; these are $94,342,652$, 683 , and 835 (not shown). IWC values for $T<-50^{\circ} \mathrm{C}$ are virtually absent (10 data points).

First, the lidar-based IWC retrieval methods by Heymsfield et al. $(2005,2014)$ are evaluated. Both have in common that they establish functional relations between retrieved IWC 
and the optical particle extinction coefficient of the kind $\mathrm{IWC}_{\mathrm{ret}}=a \alpha_{\mathrm{par}}^{b}$, with $a$ and $b$ being either independent of $T$ :

$$
\begin{aligned}
& \mathrm{IWC}=119 \alpha_{\mathrm{par}}^{1.22}, \\
& \mathrm{IWC}=527 \alpha_{\text {par }}^{1.32},
\end{aligned}
$$

or dependent on $T$ :

$$
\begin{aligned}
\mathrm{IWC} & =[89+(0.6204 T)] \alpha_{\mathrm{par}}^{(1.02-0.00281 T)}, \\
\mathrm{IWC} & =0.00532(T+90)^{2.55} \alpha_{\mathrm{par}}^{[1.31 \exp (0.0047 T)]} .
\end{aligned}
$$

Equations (17) and (19) are taken from Heymsfield et al. (2005), and Eqs. (18) and (20) from Heymsfield et al. (2014).

They differ in the way how they derive $\alpha_{\text {par }}$ from the in situ measurements of cirrus clouds with particle probes, and the selection of the aircraft campaigns analyzed.

The in situ data used in the study by Heymsfield et al. (2005) have been obtained mainly in low-latitude ice clouds produced by deep convection, but measurements in thin tropical and northern midlatitude synoptically generated cirrus are also included. Noteworthily, in the temperature range of the RAMSES measurements the data exhibit a strong dependence on geographical location. Heymsfield et al. (2014) deploys a microphysical dataset which is substantially larger and more diverse. Particle measurements from 10 aircraft field programs are analyzed, spanning latitudes from the Arctic to the tropics and temperatures from $-86^{\circ}$ to $0^{\circ} \mathrm{C}$. IWC and $\alpha_{\text {par }}$ for $T>-55^{\circ} \mathrm{C}$ are from a combination of in situ-generated cirrus in midlatitudes and convectively generated cirrus at low latitudes. IWC shows a different dependence on $\alpha_{\text {par }}$ for data groups designated as warm and cold cirrus. For this reason, coefficients $a$ and $b$ are not only provided for the entire datasets but also for subsets to investigate the effects of sampling region and temperature range.

The relations of Eqs. (17)-(20) were applied to the optical extinction profiles of the pure-ice and mixed-phase clouds observed with RAMSES and then compared with the simultaneously measured IWC of which the mean profile is shown in Fig. 10. The extinction coefficient is corrected for multiple scattering following the approach of Hogan (2008). To provide optimum input information to the multiple-scattering model, the projection-area equivalent particle size is not assumed static but dynamically estimated based on ambient $T$ (Heymsfield and Platt 1984) and particle optical properties, the latter to account for particle phase and spatial alignment. Figure 11 illustrates the performance of the lidar-based IWC retrievals. Shown is the relative difference between retrieved and measured IWC as a function of IWC $_{\text {RAMSES. The red }}$ curves highlight mean differences of the $T$-dependent relations (with error bars) and the blue curves those of the $T$ independent relations. The corresponding individual data points are shown as gray symbols.

In the case of Heymsfield et al. (2005), the $T$-dependent retrieval overestimates IWC by about $40 \%$ independently of IWC magnitude (Fig. 11a). The error bars are large,
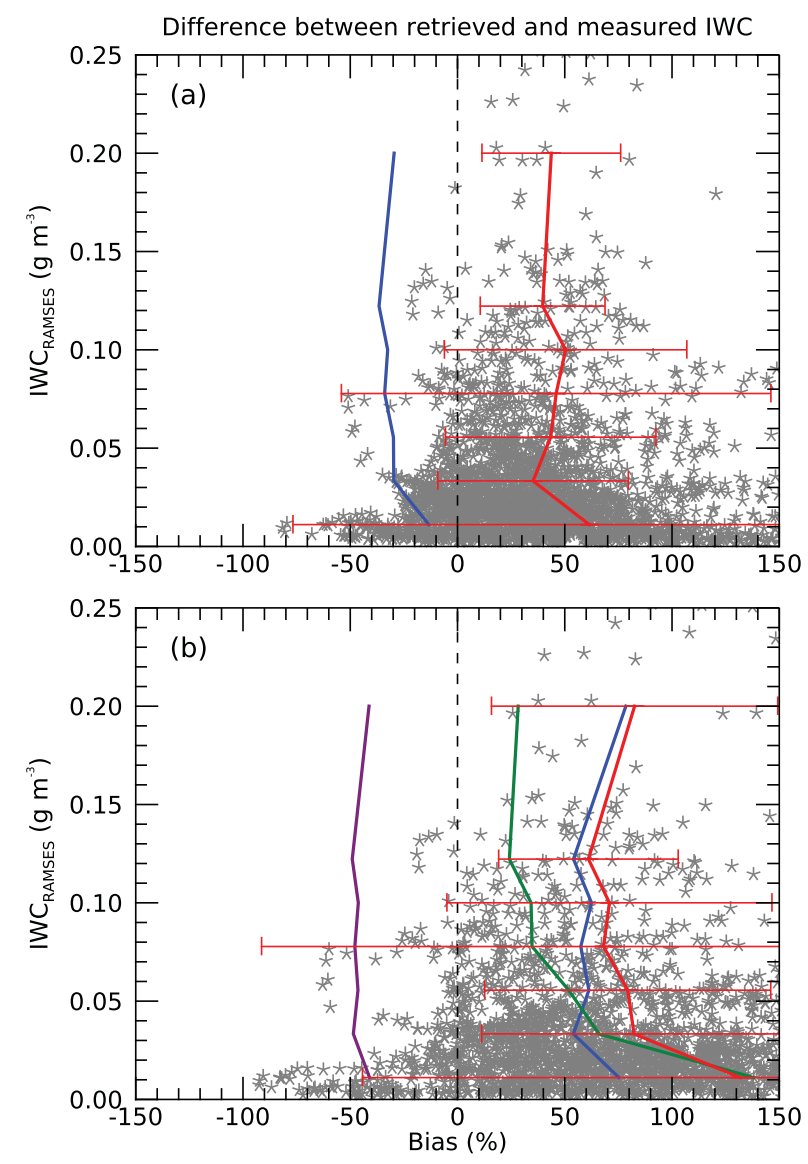

FIG. 11. Relative difference between retrieved and measured IWC [( IWC $_{\text {ret }}-$ IWC $\left._{\text {RAMSES }}\right) /$ IWC $\left._{\text {RAMSES }}\right]$ for the lidar-only IWC retrieval methods proposed by (a) Heymsfield et al. (2005) and (b) Heymsfield et al. (2014). Both parameterizations assume a power law as the functional relationship between IWC and the particle extinction coefficient, $\mathrm{IWC}_{\mathrm{ret}}=a \alpha_{\mathrm{par}}^{b}$, with $a$ and $b$ either dependent on, or independent of, temperature. Mean biases (obtained by averaging over IWC $_{\text {RAMSES }}$ segments) are presented for temperature-dependent (red curves, with error bars) and temperature-independent coefficients (blue curves). In the case of Heymsfield et al. (2014), mean biases are also shown for subsets of data designated as cold cirrus (purple curve) and warm cirrus (green curve). For illustrative purposes, biases of individual data points are visualized as well (symbols, temperature-dependent $a, b$ ).

demonstrating that while on average the retrieval may be seen as satisfactory, for a specific measurement deviations from the true IWC value can be substantial. In contrast, the $T$-independent retrieval underestimates IWC by about $30 \%$. This is to be expected, because in the RAMSES IWC dataset relatively warm cirrus temperatures are predominant, and, for given $\alpha_{\text {par }}$, the IWC values of the two retrievals increasingly differ with temperature, with the $T$-independent IWC being smaller.

The $T$-dependent retrieval of Heymsfield et al. (2014) overestimates IWC even more (by at least $60 \%$ ) and exhibits an IWC-dependent bias (Fig. 11b). This trend is removed when the $T$-independent retrieval (all cirrus data) is used; however, 
biases are still larger than in Fig. 11a. Obviously, the temperature dependence in the in situ cirrus data is different from the one at midlatitudes, and corrections for it have even counterproductive effects. As mentioned before, the in situ dataset used by Heymsfield et al. (2014) to derive the lidar optical extinction-based IWC retrievals [Eqs. (18) and (20)] obviously consists of two subsets that result in very different relationships between IWC and $\alpha_{\text {par }}$. Therefore, the question arises whether the combination of both datasets makes sense at all. Heymsfield et al. (2014) themselves point out this problem, and consequently provide separate fit parameter sets for the two groups, for which the bias profiles are also shown in Fig. 11b [warm cirrus: $a=79.0, b=1.04$; cold cirrus: $a=$ $164.07, b=1.31)$. Good performance is observed for the warm-cirrus retrieval for IWC $>0.05 \mathrm{~g} \mathrm{~m}^{-3}$. However, IWC is significantly overestimated for smaller IWC values. The relative bias of the cold-cirrus retrieval is between $-40 \%$ and $-50 \%$, which is comparable to the results of the $T$-independent retrieval in Fig. 11a.

In conclusion, the comparison suggests that there is no universal relationship between IWC, $T$, and $\alpha_{\text {par }}$, but that it depends on the geographical location and possibly also on the type of the cirrus clouds sampled for the underlying dataset. Obviously, both retrieval methods are not applicable to northern midlatitude cirrus without empirical corrections. Other adverse effects on IWC retrievals that use lidar data are conceivable as well, for instance, particle orientation (Khanal and Wang 2015), but are probably of lesser impact.

Next we evaluate the cloud radar-based IWC retrieval by Hogan et al. (2006). This IWC retrieval is used in the Cloudnet retrieval scheme as a standard product for the comparison with cloud data from various weather forecast models (Illingworth et al. 2007). Similar to the Heymsfield et al. (2005, 2014) lidar methods, Hogan et al. (2006) analyzed in situ probes for their ice size distributions and derived relationships between $Z$, IWC, and temperature depending on the radar frequency, but here the aircraft datasets originate from the northern midlatitudes. Using a mass-size relationship, the relation between IWC and $35 \mathrm{GHz}$ reflectivity factor and temperature is the following (Hogan et al. 2006):

$$
\log _{10} \mathrm{IWC}=0.000242 Z T+0.0699 Z-0.0186 T-1.63 .
$$

MIRA-35, the $35 \mathrm{GHz}$ pulsed polarimetric Doppler radar of the Lindenberg Meteorological Observatory (Görsdorf et al. 2015), is located at a distance of about $200 \mathrm{~m}$ from RAMSES. We applied relation (21) to the MIRA-35 $Z$ measurements of the pure-ice and mixed-phase clouds to retrieve IWC; the temperature profiles were taken from a weather prediction model. The cloud radar-based IWC estimates were then compared with the RAMSES IWC measurements. It is generally expected that the radar reflectivity-based algorithms will produce biased results, because cloud radar calibration constitutes a major challenge. In the case of MIRA-35, the manufacturer performed a budget calibration before delivery in April 2004, which means that gain and loss of all components were determined separately to estimate the radar constant. Varying parameters (e.g., transmit power) are measured

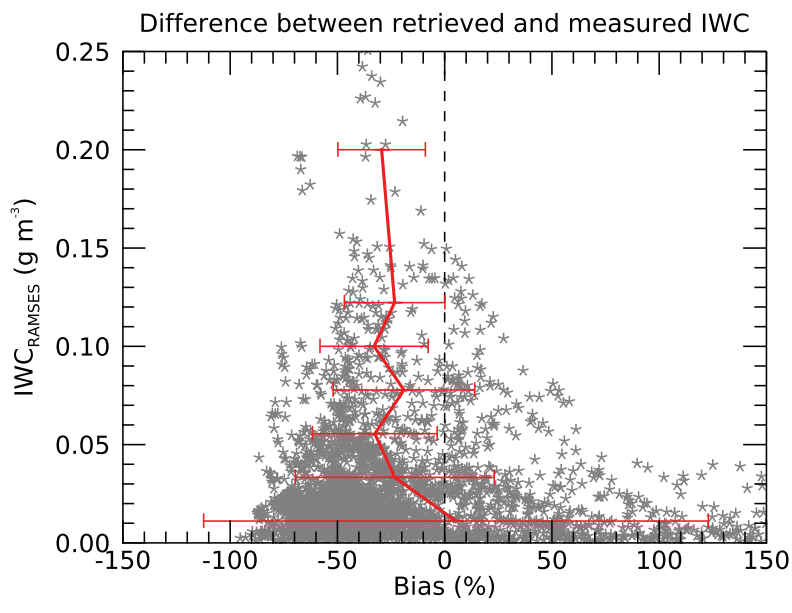

FIG. 12. As in Fig. 11, but for the radar-only IWC retrieval method proposed by Hogan et al. (2006). The parameterization assumes a functional relationship between IWC and the radar reflectivity and ambient temperature.

during the operation; however, the aging of electronic components and transient technical malfunctions can still lead to a drift, or variations, in the radar constant and thus to a reduction in the accuracy of $Z$. To account for these systematic errors, comparisons between MIRA-35 and a collocated $24 \mathrm{GHz}$ micro rain radar are performed on a routine basis in rain events for altitudes of $500 \mathrm{~m}$ and a reflectivity range between about 0 and $20 \mathrm{dBZ}$. The mean differences vary between about -6.0 and $-3.3 \mathrm{~dB}$ over time, the $Z$ measurements with MIRA-35 are corrected accordingly.

Figure 12 shows the IWC comparison. The scatter of data points is significantly smaller than with the lidar-based methods discussed above, which is reflected in lower errors. Overall, the radar-only retrieval tends to underestimate IWC slightly. For all IWC, the mean dry bias is between $20 \%$ and $30 \%$, or smaller. In view of the indirectness of the radar method, this can be regarded as remarkably good performance, at least on average. But the scatter of the individual biases cautions that even with a well-calibrated cloud radar only rough estimates of IWC can be obtained: retrieved and true IWC values can easily differ by a factor of 2.

\section{Summary and outlook}

Continuing the work of R14, a detailed description has been given of how the LWC and the IWC can be determined accurately and absolutely from the calibrated water Raman spectra of clouds. All instrumental and spectroscopic parameters that affect the accuracy of the watercontent measurement have been discussed and quantified, starting with the careful characterization of the RAMSES water spectrometer. One important factor that determines the accuracy of the water-content measurement is the molecular Raman backscattering efficiency of cloud particles. For water droplets, a rigorous theoretical approach 
combined with massive computing have yielded $\eta_{\text {liq }}$ values of $2.2 \pm 0.2$ for drizzle and light rain and $2.63 \pm 0.07$ for nonprecipitating clouds. Furthermore, the effect of shape oscillations on $\eta_{\text {liq }}$ has been studied. For the nonspheroidal particles of ice clouds, such a theoretical approach does not exist and modeling efforts have proven to be extremely challenging, so an experimental method had to be developed. It is based on the assumption of continuity of the number of water molecules over the vertical extent of melting layers. Several strict selection criteria were defined to select the RAMSES measurement that best meets this basic requirement. The analysis of this case then yielded an $\eta_{\text {ice }}$ value of $1.9 \pm 0.3$. While the problem can be regarded as solved for liquid-water clouds and light precipitation, there is still work to do for cirrus clouds, both experimentally and theoretically. It can be expected that these efforts will lead to a further reduction in the systematic uncertainty of the IWC measurement.

Examples of particularly interesting water-content measurements have been presented, including supercooled liquidwater clouds and melting layers. Error sources have been discussed. One effect that stands out is interfering fluorescence by aerosols, especially in the boundary layer (as demonstrated in this study), but also in the free troposphere (Reichardt et al. 2018a) and stratosphere (Immler et al. 2005). Aerosol effects and calibration issues are the main reasons why spectral Raman measurements are required for quantitative measurements of LWC and IWC, the use of discrete detection channels is insufficient to solve the associated problems.

Finally, IWC retrieval methods have been evaluated that are based on either lidar extinction or radar reflectivity measurements. It turns out that the lidar-based retrievals proposed by Heymsfield et al. $(2005,2014)$ show unsatisfactory agreement with the RAMSES IWC measurements. The reason is likely that the in situ dataset that was used to determine IWC and extinction coefficient cannot be considered geographically representative for the RAMSES measurements at midlatitudes, but other effects such as particle orientation might also play a role. In contrast, the radar-based IWC retrieval of Hogan et al. (2006) performs reasonably well. For individual measurements, the retrieval error is significantly lower than for the lidar-only retrievals, and on average retrieved IWC agrees within $20 \%$ to $30 \%$ (dry bias) with measured IWC. Currently, evaluation of retrieval methods is extended to multisensor retrievals.

In summary, with this study the groundwork has been laid for direct measurements of atmospheric water in all of its three phases with spectrometric Raman lidar such as RAMSES, the operational high-performance multiparameter Raman lidar at the Lindenberg Meteorological Observatory site. RAMSES is thus well suited for future cloud microphysical studies, and for evaluating cloud models or the cloud data products of other instruments. Furthermore, especially after the upgrade of the instrument with two fluorescence spectrometers (Reichardt et al. 2018a,b), investigations into the coexistence of, or interaction between, clouds and aerosols can be performed as well.

A disadvantage of spectrometric lidar measurements is that such measurements are only possible at night, under favorable atmospheric conditions and often only in the lower cloud ranges (up to an optical depth of approximately 2) because the Raman return signals from clouds are extremely weak, which makes them particularly vulnerable to background light and light extinction. To overcome these limitations, efforts are made to develop a retrieval technique which allows one to obtain estimates of IWC under all measurement conditions. The work is ongoing, but initial results are encouraging as first applications demonstrate (Strandgren 2018; Rybka et al. 2021).

\section{REFERENCES}

Arshinov, Y. F., S. M. Bobrovnikov, A. I. Nadeev, I. B. Serikov, D. Kim, H. Cha, and K. Song, 2002: Observation of rangeresolved rovibrational Raman spectra of water in clean air and in a cloud with a 32-spectral-channel Raman lidar. Proc. 21st Int. Laser Radar Conf., Quebec City, QC, Canada, ICLAS, 31-34.

Auguié, B., W. R. C. Somerville, S. Roache, and E. C. L. Ru, 2016: Numerical investigation of the Rayleigh hypothesis for electromagnetic scattering by a particle. J. Opt., 18, 075007, https://doi.org/10.1088/2040-8978/18/7/075007.

Avila, G., J. M. Fernández, B. Maté, G. Tejeda, and S. Montero, 1999: Ro-vibrational Raman cross sections of water vapor in the $\mathrm{OH}$ stretching region. J. Mol. Spectrosc., 196, 77-92, https://doi.org/10.1006/jmsp.1999.7854.

Baker, M. B., 1997: Cloud microphysics and climate. Science, 276, 1072-1078, https://doi.org/10.1126/science.276.5315.1072.

Bukin, O. A., U. K. Kopvillem, S. Y. Stolyarchuk, and V. A. Tyapkin, 1983: Investigation of Raman spectra of atmospheric gases. J. Appl. Spectrosc., 38, 561-564, https://doi.org/ 10.1007/BF00658788.

D'Arrigo, G., G. Maisano, F. Mallamace, P. Migliardo, and F. Wanderlingh, 1981: Raman scattering and structure of normal and supercooled water. J. Chem. Phys., 75, 4264-4270, https:// doi.org/10.1063/1.442629.

Deirmendjian, D., 1975: Far-infrared and submillimeter wave attenuation by clouds and rain. J. Appl. Meteor., 14, 1584-1593, https://doi.org/10.1175/1520-0450(1975)014<1584:FIASWA >2. $0 . \mathrm{CO} ; 2$.

Delanoë, J., and R. J. Hogan, 2008: A variational scheme for retrieving ice cloud properties from combined radar, lidar, and infrared radiometer. J. Geophys. Res., 113, D07204, https://doi.org/10.1029/2007JD009000.

Di Girolamo, P., D. Summa, M. Cacciani, E. G. Norton, G. Peters, and Y. Dufournet, 2012: Lidar and radar measurements of the melting layer: Observations of dark and bright band phenomena. Atmos. Chem. Phys., 12, 4143-4157, https://doi.org/10.5194/acp-12-4143-2012.

Donovan, D. P., and A. C. A. P. van Lammeren, 2001: Cloud effective particle size and water content profile retrievals using combined lidar and radar observations: 1 . Theory and examples. J. Geophys. Res., 106, $27425-27448$, https://doi.org/ 10.1029/2001JD900243.

Gaussiat, N., H. Sauvageot, and A. Illingworth, 2003: Cloud liquid water and ice content retrieval by multiwavelength radar. $J$. Atmos. Oceanic Technol., 20, 1264-1275, https://doi.org/10. 1175/1520-0426(2003)020<1264:CLWAIC>2.0.CO;2.

Görsdorf, U., V. Lehmann, M. Bauer-Pfundstein, G. Peters, D. Vavriv, V. Vinogradov, and V. Volkov, 2015: A 35-GHz polarimetric Doppler radar for long-term observations of 
cloud parameters-Description of system and data processing. J. Atmos. Oceanic Technol., 32, 675-690, https://doi.org/ 10.1175/JTECH-D-14-00066.1.

Gröbner, J., N. Kouremeti, and S. Kazadzis, 2016: ATLAS-A pulsed tunable laser system for the characterization of spectrometers. PMOD/WRC Annual Rep. 2015, 37.

Harvey, A. H., J. S. Gallagher, and J. M. H. Levelt Sengers, 1998: Revised formulation for the refractive index of water and steam as a function of wavelength, temperature and density. J. Phys. Chem. Ref. Data, 27, 761-774, https://doi.org/10.1063/ 1.556029.

Heymsfield, A. J., and C. M. R. Platt, 1984: A parameterization of the particle size spectrum of ice clouds in terms of the ambient temperature and the ice water content. J. Atmos. Sci., 41, 846-855, https://doi.org/10.1175/1520-0469(1984)041<0846: APOTPS $>2.0 . \mathrm{CO} ; 2$.

- D. Dinker, and G.-J. van Zadelhoff, 2005: Extinction-ice water content-effective radius algorithms for CALIPSO. Geophys. Res. Lett., 32, L10807, https://doi.org/10.1029/ 2005 GL022742.

— - - M. Avery, M. Vaughan, G. Diskin, M. Deng, V. Mitev, and R. Matthey, 2014: Relationships between ice water content and volume extinction coefficient from in situ observations for temperatures from $0^{\circ}$ to $-86^{\circ} \mathrm{C}$ : Implications for spaceborne lidar retrievals. J. Appl. Meteor. Climate, 53, 479-505, https://doi.org/10.1175/JAMC-D-13-087.1.

Hogan, R. J., 2008: Fast lidar and radar multiple-scattering models. Part I: Small-angle scattering using the photon variance-covariance method. J. Atmos. Sci., 65, 3621-3635, https://doi. org/10.1175/2008JAS2642.1.

_, M. P. Mittermaier, and A. J. Illingworth, 2006: The retrieval of ice water content from radar reflectivity factor and temperature and its use in evaluating a mesoscale model. $J$. Appl. Meteor. Climate, 45, 301-317, https://doi.org/10.1175/ JAM2340.1.

Illingworth, A. J., and Coauthors, 2007: Cloudnet: Continuous evaluation of cloud profiles in seven operational models using ground-based observations. Bull. Amer. Meteor. Soc., 88, 883-898, https://doi.org/10.1175/BAMS-88-6-883.

Immler, F., D. Engelbart, and O. Schrems, 2005: Fluorescence from atmospheric aerosol detected by a lidar indicates biogenic particles in the lowermost stratosphere. Atmos. Chem. Phys., 5, 345-355, https://doi.org/10.5194/acp-5-345-2005.

Intrieri, J. M., G. L. Stephens, W. L. Eberhard, and T. Uttal, 1993: A method for determining cirrus cloud particle sizes using lidar and radar backscatter technique. J. Appl. Meteor., 32, 1074-1082, https://doi.org/10.1175/1520-0450(1993)032<1074: AMFDCC $>2.0 . \mathrm{CO} ; 2$.

Khanal, S., and Z. Wang, 2015: Evaluation of the lidar-radar cloud ice water content retrievals using collocated in situ measurements. J. Appl. Meteor. Climate, 54, 2087-2097, https://doi.org/10.1175/JAMC-D-15-0040.1.

Kim, D., S. Baik, H. Cha, Y. Kim, and I. Song, 2009: Lidar measurement of a full Raman spectrum of water by using a multichannel detector. J. Korean Phys. Soc., 54, 38-43, https://doi. org/10.3938/jkps.54.38.

Liu, F., and F. Yi, 2013: Spectrally resolved Raman lidar measurements of gaseous and liquid-water in the atmosphere. Appl. Opt., 52, 6884-6895, https://doi.org/10.1364/AO.52.006884.

Ovtchinnikov, M., and Y. Kogan, 2000: Evaluation of radar retrieval algorithms in stratiform clouds using large-eddy simulations. J. Geophys. Res., 105, 17351-17359, https://doi.org/ 10.1029/2000JD900216.
Pappalardo, G., 2018: ACTRIS aerosol, clouds and trace gases research infrastructure. EPJ Web Conf., 176, 09004, https:// doi.org/10.1051/epjconf/201817609004.

Park, S.-H., Y.-G. Kim, D. Kim, H.-D. Cheong, W.-S. Choi, and J.-I. Lee, 2010: Selecting characteristic Raman wavelengths to distinguish liquid-water, water vapor, and ice water. J. Opt. Soc. Korea, 14, 209-214, https://doi.org/10.3807/JOSK.2010.14. 3.209 .

Penney, C. M., and M. Lapp, 1976: Raman-scattering cross sections for water vapor. J. Opt. Soc. Amer., 66, 422-425, https:// doi.org/10.1364/JOSA.66.000422.

Pershin, S. M., and A. F. Bunkin, 1998: A "jump" in the position and width of the Raman band envelope of $\mathrm{O}-\mathrm{H}$ valence vibrations upon phase transitions of the first and second kinds in water. Opt. Spectrosc., 85, 190-193.

Plakhotnik, T., and J. Reichardt, 2017: Accurate absolute measurements of the Raman backscattering differential cross-section of water and ice and its dependence on the temperature and excitation wavelength. J. Quant. Spectrosc. Radiat. Transfer, 194, 58-64, https://doi.org/10.1016/j.jqsrt.2017.03.023.

_ , and — 2018: Relation between Raman backscattering from droplets and bulk water: Effect of refractive index dispersion. J. Quant. Spectrosc. Radiat. Transfer, 208, 172-178, https://doi.org/10.1016/j.jqsrt.2018.01.012.

Plass, G. N., and G. W. Kattawar, 1971: Reflection of light pulses from clouds. Appl. Opt., 10, 2304-2310, https://doi.org/10. 1364/AO.10.002304.

Reichardt, J., 2012: Raman backscatter-coefficient spectra of cirrus ice. Proc. 26th Int. Laser Radar Conf., Porto Heli, Greece, ICLAS, 387-390.

- 2014: Cloud and aerosol spectroscopy with Raman lidar. $J$. Atmos. Oceanic Technol., 31, 1946-1963, https://doi.org/10. 1175/JTECH-D-13-00188.1.

—, U. Wandinger, V. Klein, I. Mattis, B. Hilber, and R. Begbie, 2012: RAMSES: German Meteorological Service autonomous Raman lidar for water vapor, temperature, aerosol, and cloud measurements. Appl. Opt., 51, 8111-8131, https://doi. org/10.1364/AO.51.008111.

, R. Leinweber, and A. Schwebe, 2018a: Fluorescing aerosols and clouds: Investigations of co-existence. EPJ Web Conf., 176, 05010, https://doi.org/10.1051/epjconf/201817605010.

— J. Stäudle, R. Begbie, B. Hilber, B. Stein, N. Kouremeti, and J. Gröbner, 2018b: Spectral characterization of the new UV fluorescence spectrometer of RAMSES, the German Meteorological Service's Raman lidar for moisture sensing. Proc. First European Lidar Conf., Thessaloniki, Greece, ELC.

Rizi, V., M. Iarlori, G. Rocci, and G. Visconti, 2004: Raman lidar observations of cloud liquid water. Appl. Opt., 43, 6440-6453, https://doi.org/10.1364/AO.43.006440.

Rybka, H., and Coauthors, 2021: The behavior of high-CAPE (convective available potential energy) summer convection in large-domain large-eddy simulations with ICON. Atmos. Chem. Phys., 21, 4285-4318, https://doi.org/10.5194/acp-214285-2021.

Sakai, T., D. N. Whiteman, F. Russo, D. D. Turner, I. Veselovskii, S. H. Melfi, T. Nagai, and Y. Mano, 2013: Liquid water cloud measurements using the Raman lidar technique: Current understanding and future research needs. J. Atmos. Oceanic Technol., 30, 1337-1353, https://doi.org/10.1175/JTECH-D-1200099.1. 
Shettle, E. P., 1990: Models of aerosols, clouds and precipitation for atmospheric propagation studies. Proc. AGARD Conf., Copenhagen, Denmark, NATO.

Slusher, R. B., and V. E. Derr, 1975: Temperature dependence and cross sections of some Stokes and anti-Stokes Raman lines in ice Ih. Appl. Opt., 14, 2116-2120, https://doi.org/10. 1364/AO.14.002116.

Somerville, W. R. C., W. Auguié, and E. C. L. Ru, 2016: SMARTIES: User-friendly codes for fast and accurate calculations of light scattering by spheroids. J. Quant. Spectrosc. Radiat. Transfer, 174, 39-55, https://doi.org/10.1016/j.jqsrt. 2016.01.005.

Strandgren, J., 2018: The life cycle of anvil cirrus clouds from a combination of passive and active satellite remote sensing. Ph.D. thesis, Ludwig-Maximilians-Universität München, 148 pp., https://doi.org/10.5282/edoc.22789.

Suzuki, H., Y. Matsuzaki, A. Muraoka, and M. Tachikawa, 2012: Raman spectroscopy of optically levitated supercooled water droplet. $J$. Chem. Phys., 136, 234508, https://oi.org/10.1063/1.4729476.

Szakáll, M., S. K. Mitra, K. Diehl, and S. Borrmann, 2010: Shapes and oscillations of falling raindrops-A review. Atmos. Res., 97, 416-425, https://doi.org/10.1016/j.atmosres.2010.03.024.

Tsamopoulos, J. A., and R. A. Brown, 1983: Nonlinear oscillations of inviscid drops and bubbles. J. Fluid Mech., 127, 519-537, https://doi.org/10.1017/S0022112083002864.

Veselovskii, I. A., H. K. Cha, D. H. Kim, S. C. Choi, and J. M. Lee, 2000: Raman lidar for the study of liquid water and water vapor in the troposphere. Appl. Phys., 71B, 113-117, https://doi.org/10.1007/s003400000290.

- V. Griaznov, A. Kolgotin, and D. N. Whiteman, 2002: Angle- and size-dependent characteristics of incoherent Raman and fluorescent scattering by microspheres. 2. Numerical simulation. Appl. Opt., 41, 5783-5791, https://doi.org/10. 1364/AO.41.005783.

Wang, Z., and K. Sassen, 2002: Cirrus cloud microphysical property retrieval using lidar and radar measurements. Part I: Algorithm description and comparison with in situ data. $J$. Appl. Meteor., 41, 218-229, https://doi.org/10.1175/15200450(2002)041<0218:CCMPRU>2.0.CO;2.

—, D. N. Whiteman, B. B. Demoz, and I. Veselovskii, 2004: A new way to measure cirrus cloud ice water content by using ice Raman scatter with Raman lidar. Geophys. Res. Lett., 31, L15101, https://doi.org/10.1029/2004GL020004.

Weigel, T., J. Schulte, and G. Schweiger, 2006: Inelastic scattering by particles of arbitrary shape. J. Opt. Soc. Amer., 23, 27972802, https://doi.org/10.1364/JOSAA.23.002797.

Wettlaufer, J. S., 1999: Impurity effects in the premelting of ice. Phys. Rev. Lett., 82, 2516-2519, https://doi.org/10.1103/ PhysRevLett.82.2516.

Whiteman, D. N., and S. H. Melfi, 1999: Cloud liquid water, mean droplet radius, and number density measurements using a Raman lidar. J. Geophys. Res., 104, 31411-31419, https://doi. org/10.1029/1999JD901004. 